\title{
أثر الاستثمار الأجنبي علي الأستثمار المحلي لدول خليجية مختارة
}

\author{
يعقوب عحم أحمد محمود عحم القطان \\ طالب دكتوراه بمعهد البحوث والدراسات الأفريقية - جامعة أسوان \\ عحمد عبد الحفيظ عحم \\ أستاذ الاقتصاد الزراعي وعميد كلية الزراعة - جامعة سوهاج \\ حسن موسي رضوان \\ مدرس الاقتصاد الزراعي بالمعهد العالي للتعاون والإرشاد الزراعي بأسيوط دوان
}


تهدف الدراسـة إلى تحليل وقياس أثر الاستثمار الأجنبي المباشر على

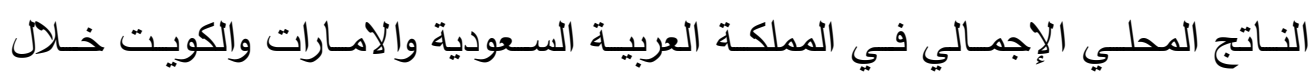

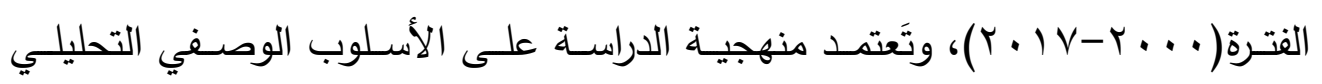

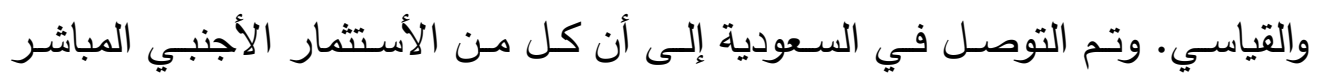

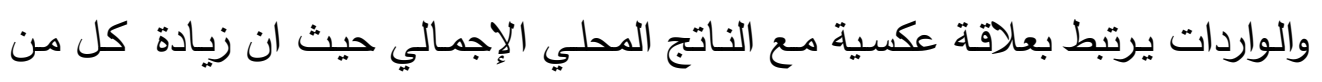

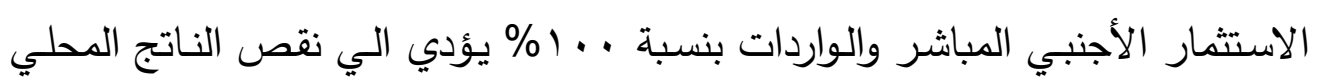

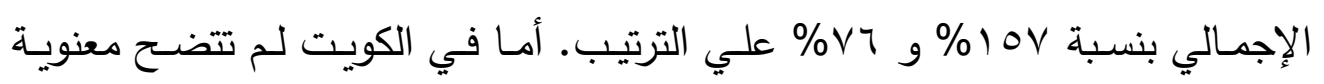

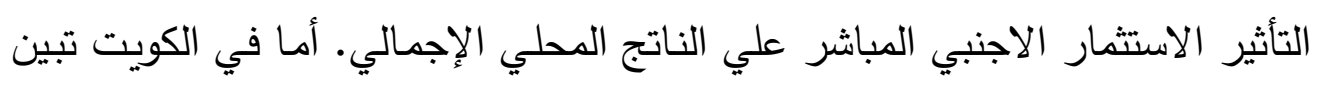

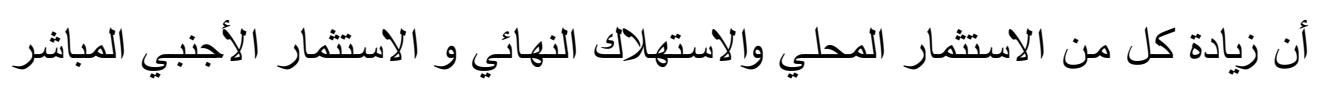

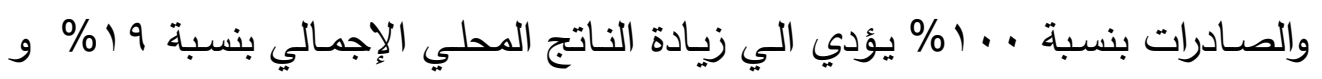

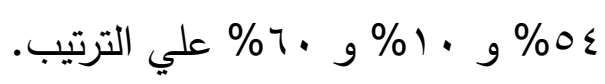
الكلمات الإفتتاحية: الأستثار الإجنبى - الأستثمار المحلى - دول الخليج

\section{Abstract:}

The impact of foreign investment on the domestic investment

\section{of selected Gulf countries}

The study aims to analyze and measure the impact of foreign direct investment on the gross domestic product in the Kingdom of Saudi Arabia, the Emirates and Kuwait during the period (2000-2017), and the methodology of the study depends on the descriptive, analytical and standard method. It was found in Saudi Arabia that both foreign direct investment and imports are related to an inverse relationship with the GDP, as increasing both foreign direct investment and imports by $100 \%$ leads to a decrease in the GDP by $157 \%$ and $76 \%$, respectively. In Kuwait, 
the significance of the effect of foreign direct investment on the gross domestic product was not clear. In Kuwait, it was found that increasing domestic investment, final consumption, foreign direct investment and exports by $100 \%$ leads to an increase in GDP by $19 \%, 54 \%, 10 \%$ and $60 \%$, respectively.

\section{المقدمة:}

تعتمد كثير من اقتصـاديات الدول في الوقت الحاضـر على استقطاب رؤوس الأموال من الخارج، وهو ما يدعى بالاستثمار الأجنبي المباشر، الذي هو عبارة عن إنشاء مشروعات جديدة في الدول المضيفة، لذا يعتبر من أحد المحركات الأساسية للنمو الاقتصادي في الدول.

يُساهم الاستثمار الأجنبي المباشر في ضـخ رؤوس الأموال في الاقتصـاد الوطني، وإنشاء المدن الصناعية وإيجاد حل لمشكلة البطالة، وتحسين الإنتاجية من خلال ما يجلبه الاستثمار من تكنولوجيا ومعدات حديثة.

\section{مشكلة الدراسة: - م}

تمـر المملكـة العربيـة السـودية والامـارات والكويـت بمرحلـة تطـور في كافـة القطاعات مما يستدعي ضـرورة الحصـول على مصـادر تمويل من الداخل والخـارج، لذلك اتجهت إلى جذب الاستثمارات الأجنبية المباشرة لتفعيل عملية التتمية بشكل اكبر والتسريع من تحقيقها. وُيلاحظ أن الاستثمار الأجنبي المباشر قد تراجع عن معدلاته، وبناءً على ذلك يمكن تلخيص مشكلة الدراسة في التساؤل الآتي: مـا مدى تأثير الاستثمار الأجنبي المباشـر على النـاتج المحلي الاجمالي في المملكة العربية السعودية والامارات والكويت ؟ 


\section{فرضية الدراسة:}

تستند فرضية الدراسة على مايلي:

"تؤدي زيـادة الاستثمار الأجنبي المباشر إلى ارتفاع معدل نمو الناتج المحلي

الإجمالي في كل من المملكة العربية السعودية والامارات والكويت".

هدف الدراسة:

تهدف الدراسـة إلى بيان أثر الاستثمار الأجنبي المباشر على الناتج المحلي

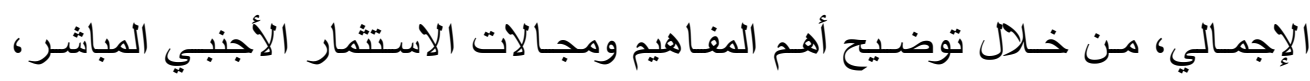

وتحديد أهميـة الاستثمار الأجنبي المباشر للوصـول من خلالهـ إلى أثره على الناتج

المحلـي الإجمـالي، واسـتعراض المحددات الاقتصـادية للاستثمار الأجنبـي المباشـر ، وقياس تأثير الاستثارات الأجنبية المباشرة على الناتج المحلي الإجمالي في كل من المملكة العربية السعودية والامـارات والكويت، من خـلال بناء نموذج قياسي يساعد على تحليل هذه العلاقة، وكذلك تسعى الدراسة في تسليط الضوء على صانعي السياسة ومتخذي القرار إلى الدور القوي الذي يؤديه الاستثمار الأجنبي المباشر في تأثيره على

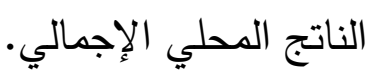

\section{أهمية الدراسةة: - 20}

تتميز الدراسـة الحالية مقارنـة بالدراسات السابقة في أنها تسلط الضوء على أثر

الاستثمار الأجنبي المباشر على الناتج المحلي الإجمالي في كل من المملكة العربية السعودية والامـارات والكويت، في حين أن الدراسـات السـابقة طبقت على دول عديدة ومختلفة، كما أن الدراسـة الحالية تَختلف عن الدراسـات السـابقة في أنها تتاولت فترة زمنية حديثة. 
نطاق الدراسة:

تُطبق هذه الدراسة في المملكة العربية السعودية والامارات والكويت بسبب الدور

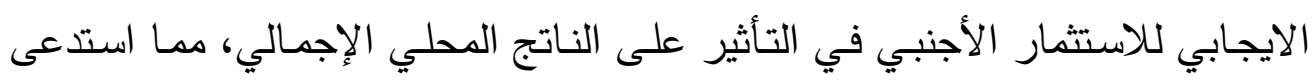

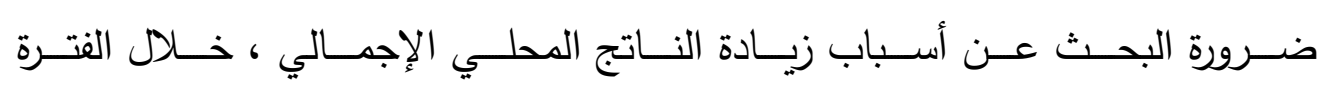

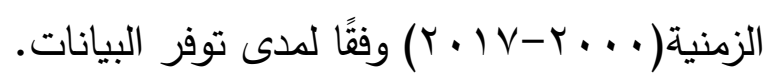

نتائج الدراسة:

المبحث الأول: توصيف نماذج عينة الدراسة:

أن الأسلوب القياسي في الاقتصاد يستهدف تقدير العلاقات الاقتصادية بثكل

كمي عن طريق توصيف علاقة رياصية بين متغيرين أو أكثر باستخدام سلسلة زمنية

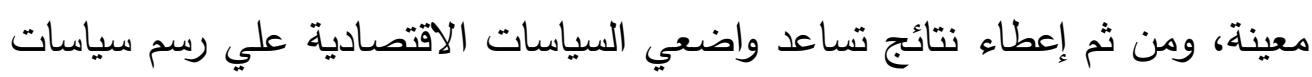
كلية تتقق مع الواقع الاقتصادي للبلد، ولغرض إثبات فرضية الدراسة الدتمثلة بوجود أثر إيجابي أو سلبي للاستثمار الأجنبي المباشر في واقع ومستقبل الاستثمار المحلي من خلال قياس علاقة بعض متغيرات الاقتصاد الكلي في البلدان المختارة، فقد تم توصيف عدد من النماذج والرموز للمتغيرات التي تم استخدامها في النماذج.

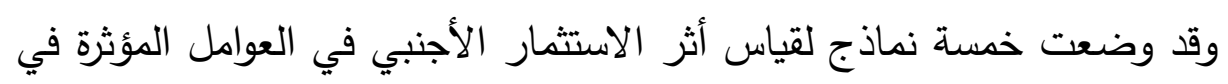

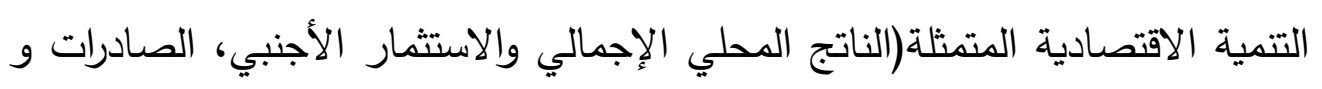

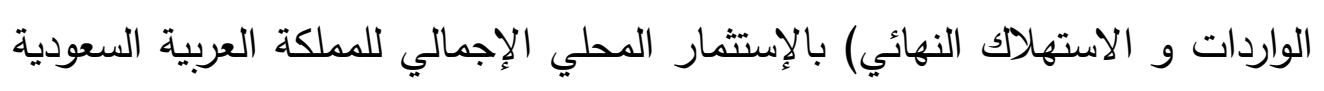

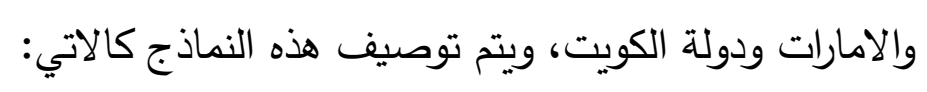
ا - النموذج الأول: يتكون هذا من ثلاثة متغيرات مستقلة بوصفها أهم العوامل المؤثرة

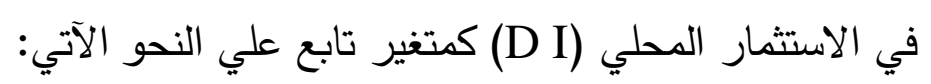
أ- الاستثمار الأجنبي المباشر (FDi): تختلف آثار الاستثمار الأجنبي المباشر علي الإني

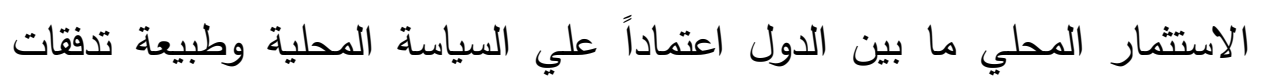


الاستثمار الأجنبي المباشر للداخل، فمن المتوقع أن يكون الاستثمار الأجنبي المباشر مضافا الي الاستثمار المحلي (إضافة الي التكوين الرأسمالي) ولا سيماإذا توجه الي القطاعات ذات المستوي التكنولوجي العالي، ولذا فإن الاستثمار الأجنبي المباشر كمتغير مستقل يرتبط عموما بعلاقة طرديا مع الاستثمار المحلي كمتغير تابع. ب- الصادرات (X): تؤدي زيادة صادرات البلد من السلع والخدمات الي زيادة حصيلته من النقد الأجنبي وبالتالي زيادة معدلات التراكم الرأسمالي اللازمة للقيام بالمشاريع الاستثمارية المحلية، ولذا فإن الصادرات كمتغير مستقل يرتبط بعلاقة طرديا مع الاستثمار المحلي كمتغير تابع. ج- الناتج المحلي الإجمالي (GDP): بما ان الناتج المحلي الإجمالي يمثل القيمة الحقيقية للدخل المحلي، الذي يوزع بين الإنفاق الاستهلاكي وما تبقي منه يذهب الي الادخار، وبالتالي فإن حصول اي زيادة في الدخرات المحلية نتيجة لزيادة الدخل القومي ستدفع المنظمين الي زيادة الجزء المخصص للاستثمار . هذا الحال يطبق علي الاقتصاديات المتقدمة، الا ان البلدان النامية تعاني من مشاكل مختلفة في مقدمتها انتشار ظاهرة الاكتناز بالنسبة للافراد وبالتالي توجيه الجزء المخصص من الدخل الي الادخار الي استخدامات غير منتجة كشراء الذهب والعقارات وبالتالي انخفاض مستوي الاستثمار المحلي، ولذا فإن الناتج المحلي الإجمالي كمتغير مستقل يرتبط بعلاقة طرديا مع الاستثمار المحلي كمتغير تابع. يمكن توصيف صيغة النموذج الأول علي النحو الآتي:

\section{$\mathrm{DI}=\mathrm{b0}+\mathrm{b} 1 \mathrm{FDi}+\mathrm{b} 2 \mathrm{X}+\mathrm{b3}$ GDP}

حيث "DI" الاستثمار المحلي( كمتغير تابع.) • 
المتغيرات المستقلة هي: "FDi" الاستثمار الأجنبي المباشر "XD" الصادرات

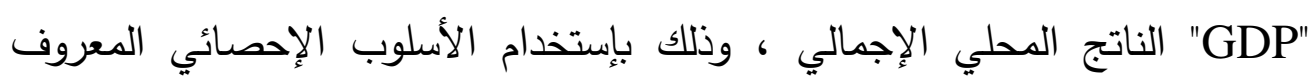

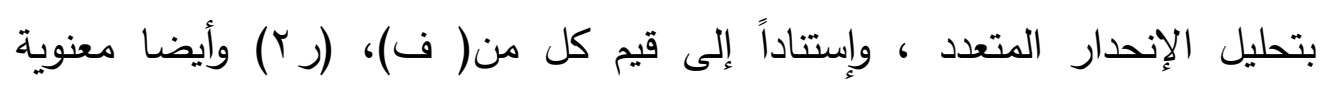

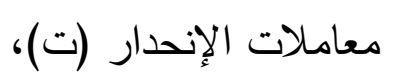

ץ- النموذج الثاني: يتكون من متغيرين مستقلين تمثل أهم العوامل المؤثرة في الناتج

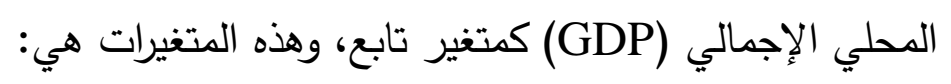
أ- الاستثمار الأجنبي المباشر (FDi): لقد أهتم التحليل الكنزي بالاسقرار الاقتصادي وعملية تحريك الطلب الفعال الذي يكفل تثغيل الطاقة الإنتاجية الفائضة والموارد

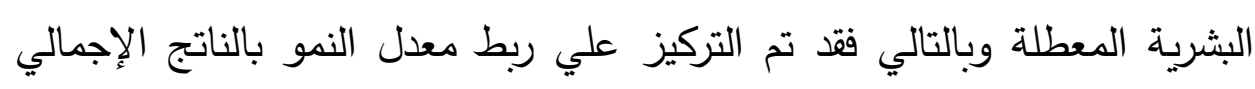
ووفقا للنظرية الاقتصادية فإن زيادة الاستثمار المحلي يؤدي الي زيادة الدخل

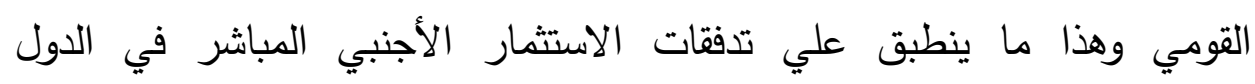
المضيفة.

ومن ذلك نسطيع القول ان هناك احتمالين لأثر الاستثار الأجنبي المباشر

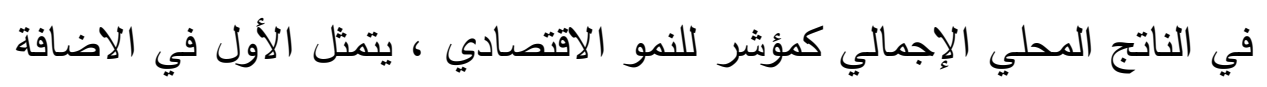

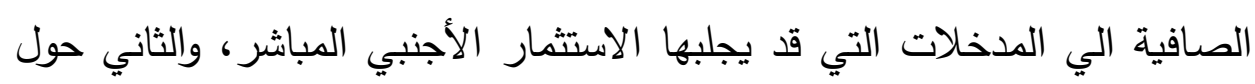
التثويه الذي قد يسببه الاستثار المباشر عن طريق المنافسة الاحتكارية، وكلا

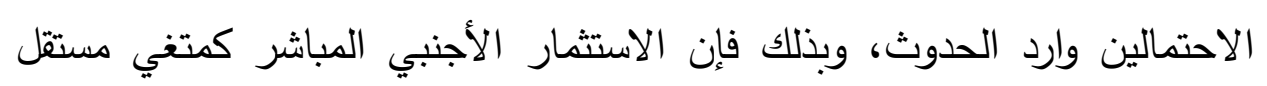

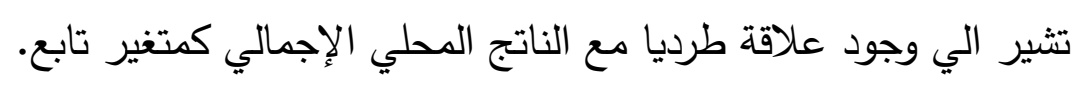

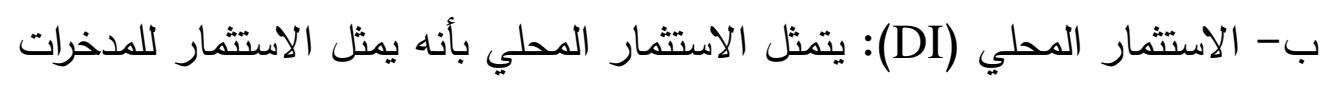

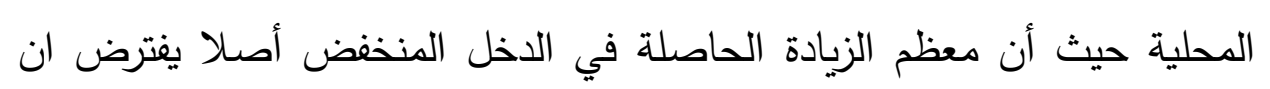
توجه نحو الاستهلاك بثكل كبير والادخار الذي يؤثر في زيادة الاستثمار المحلي، 
سيؤثر كمتغير مستقل بعلاقة طرديا فإنه يؤدي الي زيادة الناتج المحلي الإجمالي

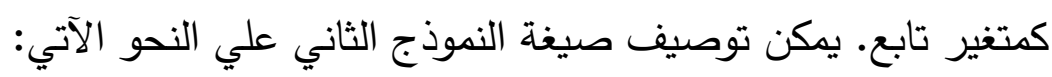

\section{GDP= b0 + b1 FDI + b2 DI}

حيث "GDP" الناتج المحلي الإجمالي ( كمتغير تابع.)

المتغيرات المستقلة هي: "FDi" الاستثمار الأجنبي المباشر "X" الصادرات

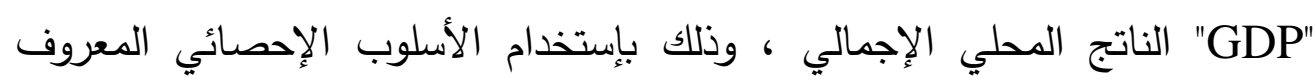

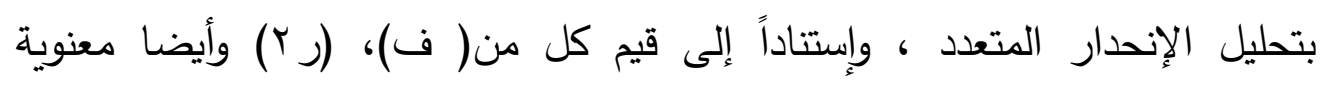

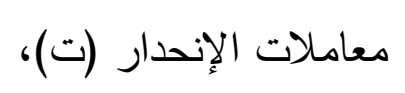

r- النموذج الثالث: يتكون هذا النموذج من ثلاثة متغيرات تمثل أهم العوامل المؤثرة

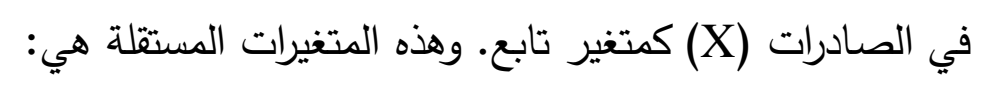

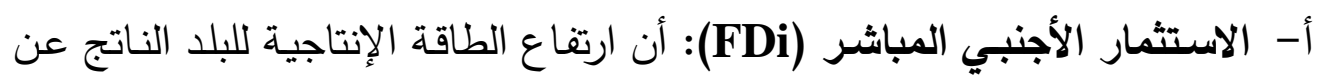

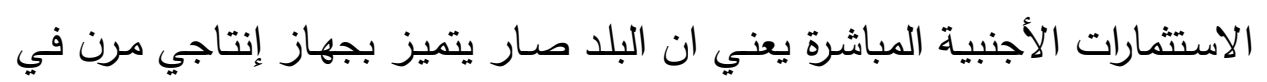

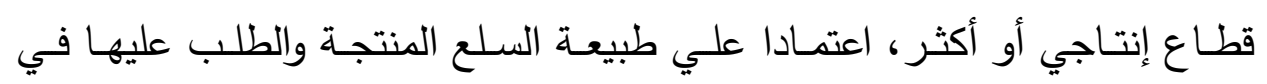

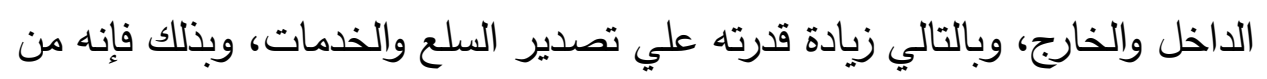

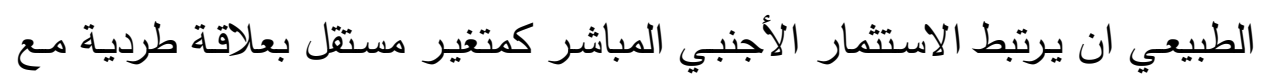

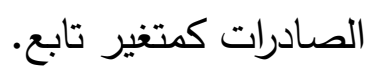

ب- الناتج المحلي الإجمالي (GDP): ان ارتفاع الناتج المحلي الإجمالي لأي بلد

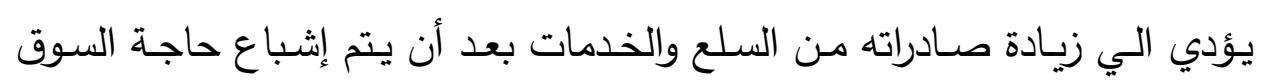

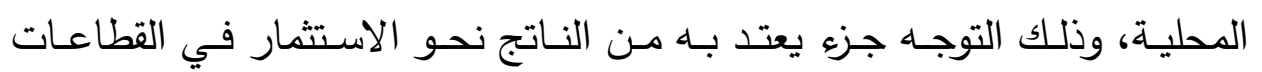

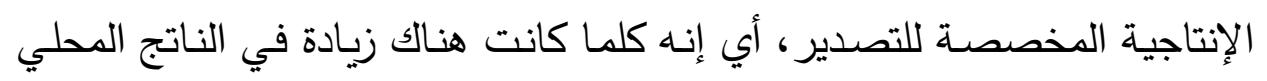

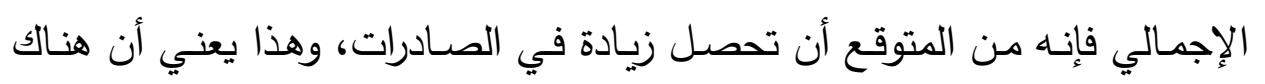

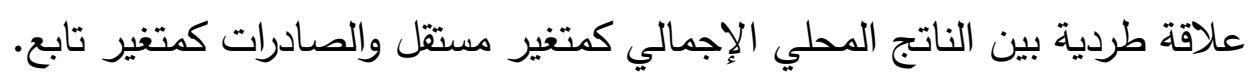

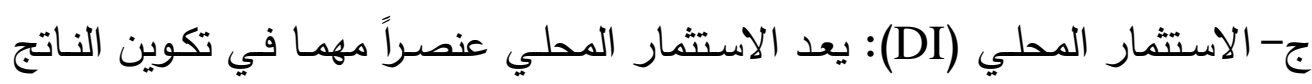

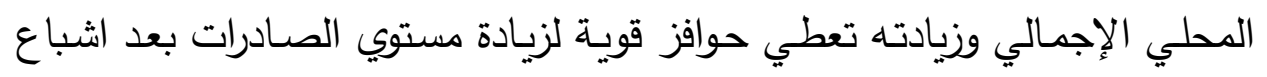




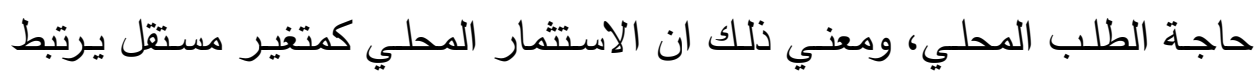

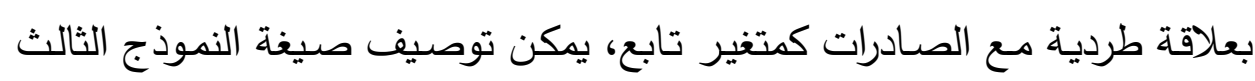

\section{$\mathrm{X}=\mathrm{b0}+\mathrm{b1}$ FDi + b2 GDP + b3 DI}

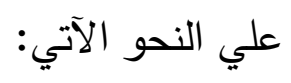

حيث "X" الصادرات ( كمتغير تابع.) •

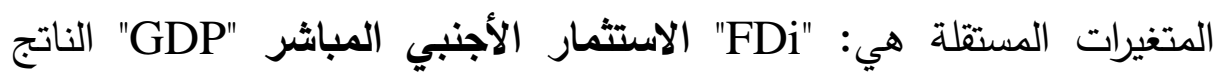

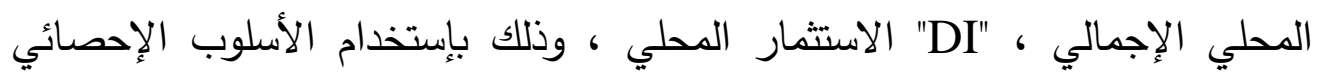

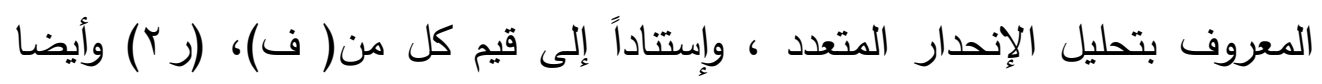

$$
\text { معنوية معاملات الإنحدار (ت). }
$$

ع - النموذج الرابع: يتكون هذا النموذج من ثلاثة متغيرات مستقلة تمثل أهم العوامل

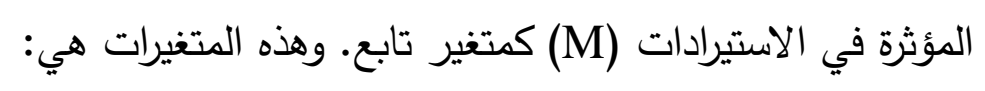

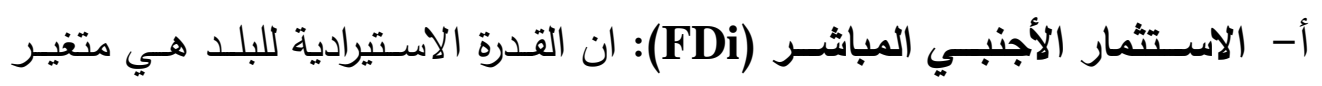

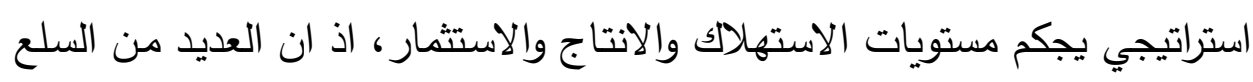

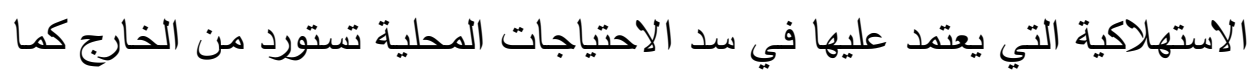

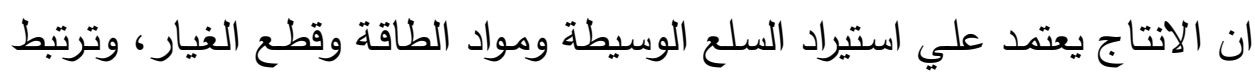

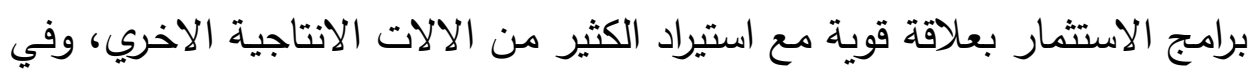

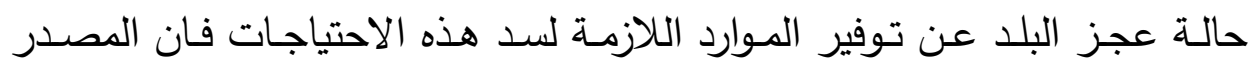

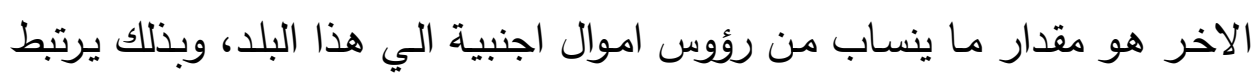

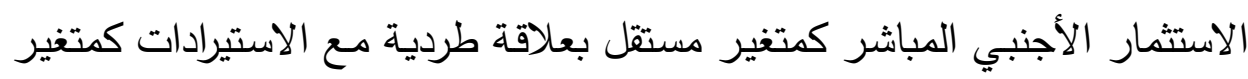
تابع.

ب- الاستهلاك المحلي (DC): ان زيادة الاستهلاك يؤثر علي زيادة الطلب بالنسبة

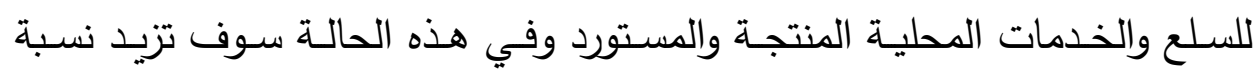

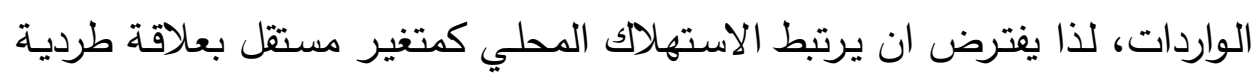
مع الواردات كمتغير تابع. 
ج- الناتج المحلي الإجمالي (GDP): ان انخفاض الناتج المحلي الاجمالي لأي بلد

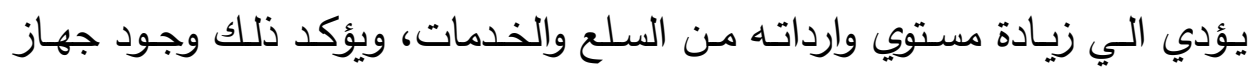
انتاجي غير مرن وغير قادر علي تلبية احتياجات البلد من السلع والخدمات

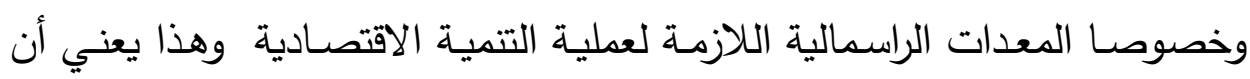

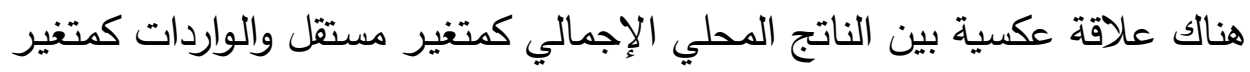

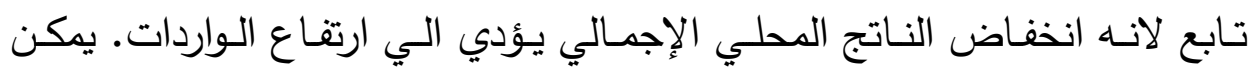

\section{M= b0 + b1 FDi + b2 DC + b3 GDP}

توصيف صيغة النموذج الرابع علي النحو الآتي:

حيث "M" الواردات ( كمتغير تابع.) .

المتغيرات المستقلة هي: "FDi" الاستثمار الأجنبي المباشر"DC" الاستهلالك الأل المحلي "GDP" الناتج المحلي الإجمالي ، وذلك بإستخدام الأسلوب الإحصائي

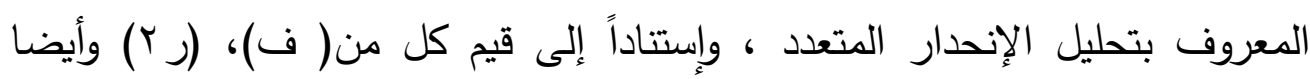

$$
\text { معنوية معاملات الإنحدار (ت). }
$$

ه- النموذج الخامس: يشمل هذا النموذج المتعدد علي جميع العوامل المستقلة والمؤثرة

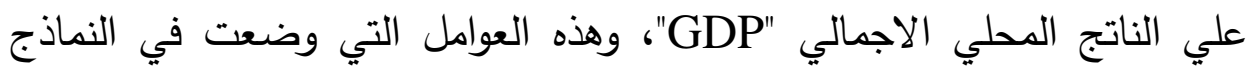
السابقة كتتغيرات مستقلة. يمكن توصيف صيغة النموذج الخامس علي النحو

\section{GDP= b0 + b1 FDI + b2 DI + b3 DC + b4 X +b5 M} الآتي:

$$
\text { حيث "GDP" الناتج المحلي الإجمالي ( كمتغير تابع.) }
$$

المتغيرات الدستقلة هي: "FDi" الاستثمار الأجنبي المباشر "DI" الاستثمار المحلي "DC" الاستهلاك المحلي X، " الصادرات، M" الواردات وذلك بإستخدام

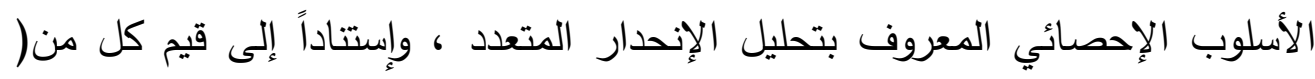

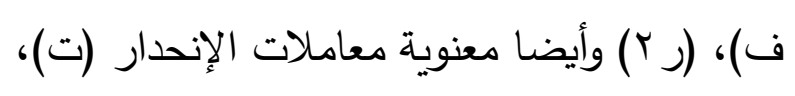


المبحث الثاني: تقدير وتحليل النتائج لنماذج عينة الدراسة:

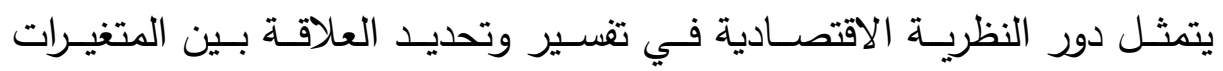

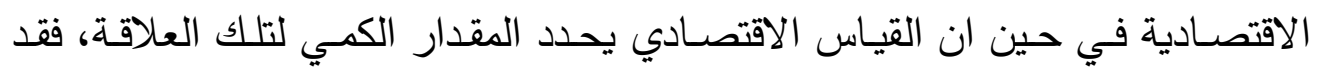

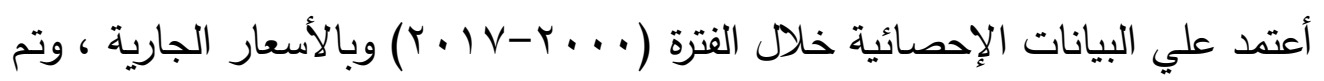

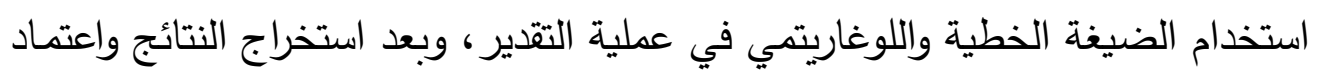

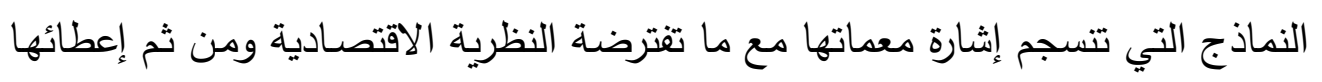

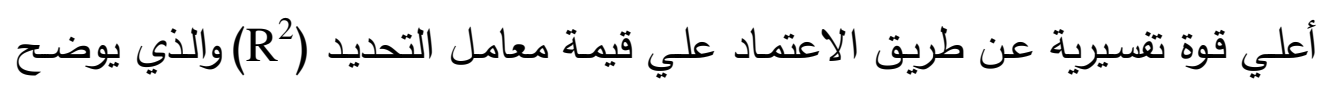

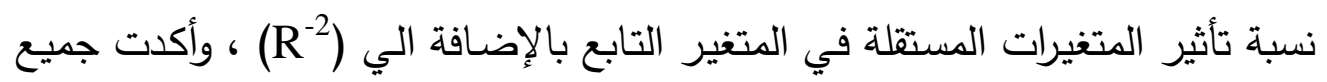

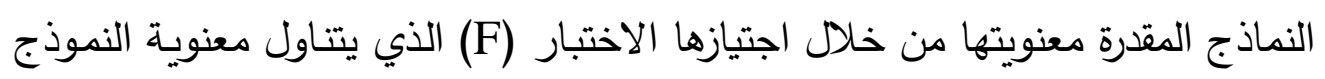
ككل.وفيما يلي تقدير للنماذج وتحليل نتائجها: 1 النموذج الأول: يتكون هذا النموذج من ثلاثة متغيرات مستقلة بوصفها أهم العوامل

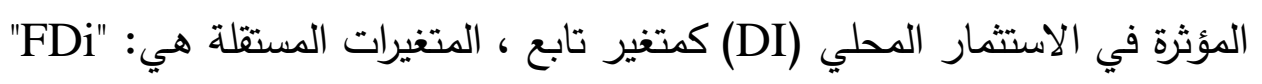

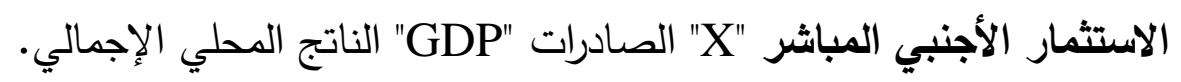

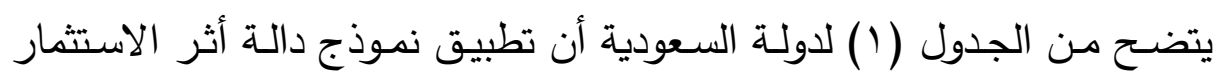
الأجنبي المباشر في الاستثمار المحلي باستخدام دالة الانحدار المتعدد، تأكد إحصائيا

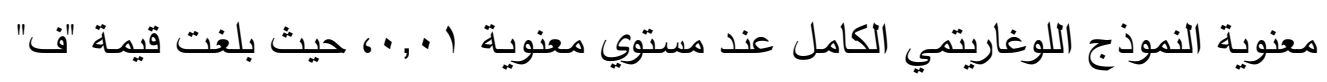

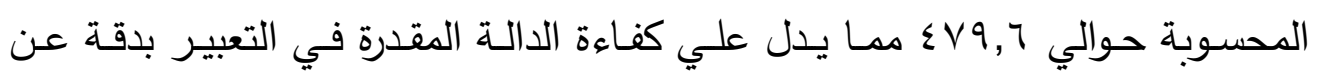

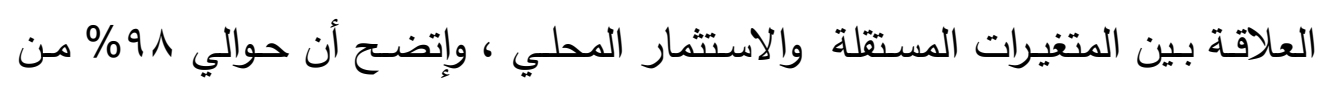

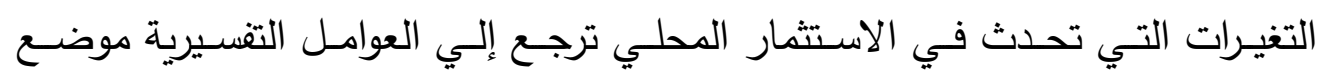

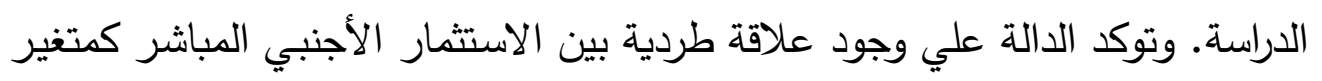

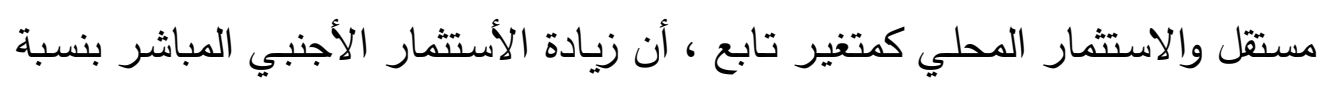

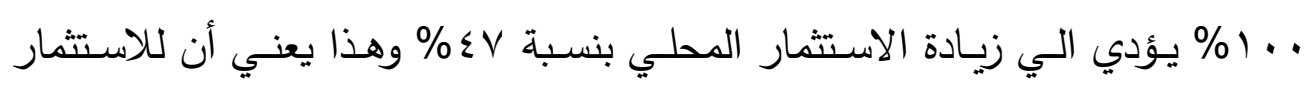

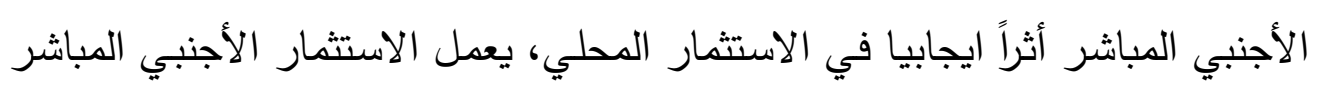


كمحفز للاستثمار المحلي، في حين يـرتط الاسـتثمار المحلي بعلاقـة عكسية مـن الصـادرات حيث ان انخفاض الصـادرات بنسبة . . 1 \% يؤدي الي زيـادة الاسـتثار المحلي بنسبة r7\% في السعودية باعتبارها دولة نفطية كلما خفضت صـادراتها من النفط زادت استثماراتها المحلية، أما الناتج المحلي الإجمالي يرتبط بعلاقة طردية مـع الاستثمار المحلي ، حيث أن زيادة الناتج المحلي الإجمالي بنسبة . . 1\% يؤدي الي زيادة الاستثمار المحلي بنسبة 119)\%

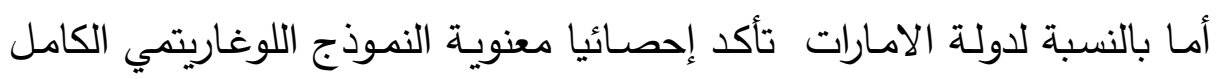

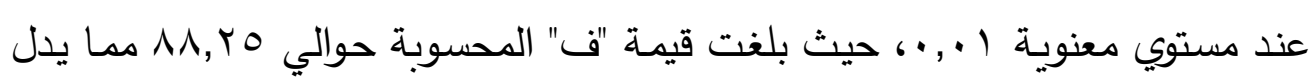
علـي كفــاءة الدالـة المقدرة فـي التعبيـر بدقـة عـن العلاقـة بـين المتغيـرات المسـتقلة والاستثمار المحلي ، وإتضح أن حوالي بو\% من التغيرات التي تحدث في الاستثمار المحلي ترجع إلـي العوامل التفسيرية موضـع الدراسـة وتوكد الدالة علي عدم معنويـة العلاقـة بين الاستثمار الأجنبي المباشر كمتغير مستقل والاستثمار المحلي كمتغير تـابع، ، في حين يـرتط الاسـتثمار المحلي بعلاقـة عكسية مـن الصـادرات حيث ان

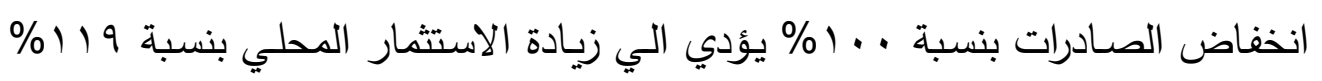
في الامارات، أما الناتج المحلي الإجمالي يرتبط بعلاقة طردية مع الاستثمار المحلي ، حيث أن زيـادة النـاتج المحلي الإجمالي بنسبة . . 1\% يـؤدي الي زيـادة الاسـثمار المحلي بنسبة أما بالنسبة لدولة الكويت تأكد إحصائيا معنوية النموذج اللوغاريتمي الكامل عند مستوي معنويـة ا .,. •، حيث بلغت قيمـة "ف" المحسوبة حوالي 0, •0 مما يدل علي كفاءة الدالة المقدرة في التعبير بدقة عن العلاقة بين المتغيرات المستقلة والاستثمار المحلي ، وإتضـح أن حوالي ^^\% من التغيرات التي تحدث في الاستثمار المحلي ترجع إلي العوامل التقسيرية موضع الدراسة وتوكد الدالة علي عدم معنويـة العلاقة بين 
الاستثمار الأجنبي المباشر كمتغير مستقل والاستثمار المحلي كمتغير تابع، ، في حين يرتط الاستثمار المحلي بعلاقة عكسية مـن الصـادرات حيث ان انخفاض الصـادرات بنسبة . . 1\% يؤدي الي زيادة الاستثمار المحلي بنسبة ه؛ (\% في دولة الكويت، أما الناتج المحلي الإجمالي يرتبط بعلاقة طردية مـع الاستثمار المحلي ، حيث أن زيـادة النـاتج المحلي الإجمـالي بنسبة . . 1\% يؤدي الي زيـادة الاسـتثمار المحلي بنسبة .\% $\wedge$ V

الجدول رقم (1) العومل المحددة للاستثمار المحلي لكل من السعودية والامارات والكويت .

\begin{tabular}{|c|c|c|c|c|c|}
\hline $\mathbf{F}$ & $\overline{\mathbf{R}^{-2}}$ & $\overline{\overline{\mathbf{R}^{2}}}$ & النموذج & نوع الدالة & الدولة \\
\hline $\begin{array}{c}274.5^{*} \\
*\end{array}$ & 0.98 & 0.98 & $\begin{array}{l}\mathrm{DI}=-30563+0.272 \mathrm{FDi}-0.294 \mathrm{X}+ \\
0.453 \mathrm{GDP} \\
(16.7)^{* *}\end{array}$ & خطية & السعودية \\
\hline $\begin{array}{c}279.6^{*} \\
*\end{array}$ & 0.98 & 0.99 & $\begin{array}{l}\mathrm{DI}=-2052+0.47 \log \mathrm{FDi}-0.62 \log \mathrm{X} \\
+1.89 \log \mathrm{GDP} \\
(17.8)^{* *} \quad(2.14)^{*} \quad(-4.9)^{* *}\end{array}$ & اللوغاريتمي & \\
\hline $41.1 * *$ & 0.87 & 0.89 & $\begin{array}{l}\mathrm{DI}=-5427-0.923 \mathrm{FDi}-0.444 \mathrm{X}+0.721 \\
\mathrm{GDP} \\
(2.91)^{* *}\end{array}$ & خطية & الامارات \\
\hline $\begin{array}{c}88.25^{*} \\
*\end{array}$ & 0.93 & 0.95 & $\begin{array}{l}\mathrm{DI}=-1.96-0.045 \log \mathrm{FDi}-1.19 \log \mathrm{X}+ \\
2.46 \log \text { GDP } \\
(10.64)^{* *} \quad(-1.03) \quad(-8.11)^{* *}\end{array}$ & اللوغاريتمي & \\
\hline $22.3 * *$ & 0.79 & 0.82 & $\begin{array}{l}\mathrm{DI}=-4791-0.479 \mathrm{FDi}-0.430 \mathrm{X}+0.488 \\
\mathrm{GDP} \\
(4.64)^{* *} \\
(-0.26) \quad(-2.76)^{*}\end{array}$ & خطية & الكويت \\
\hline $50.5^{* *} *$ & $\begin{array}{l}0.89 \\
\end{array}$ & 0.91 & 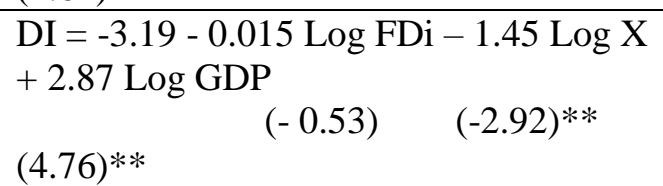 & اللوغاريتمي & \\
\hline
\end{tabular}

$$
\text { المصدر : جدول رقم (r, r, ( )بالملحق }
$$


r- النمـوذج الثاني: يتكون هذا النموذج من متغيرين مستقلة بوصفها أهم العوامل المؤثرة في الناتج المحلي الإجمالي (GDP) كمتغير تابع ، المتغيرات المستقلة هي: "FDi" الاستثمار الأجنبي المباشر "DI" الإستثمار المحلي •

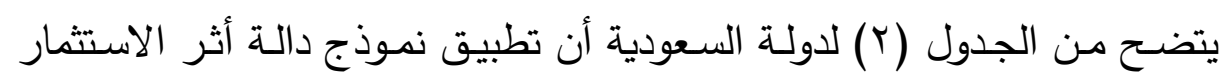
الأجنبي المباشـر والاستثمار المحلي علي النـاتج المحلي الإجمـالي باسـتخدام دالـة

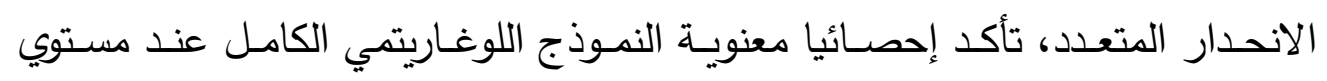
معنويـة ا +, •، حيث بلغت قيمة "ف" المحسوبة حوالي 9,9 • ب مما يدل علي كفاءة الدالـة المقدرة في التعبير بدقـة عن العلاقـة بين المتغيـرات المستقلة النـاتج المحلي الإجمـالي ، وإتضـح أن حـوالي \9\% مـن التغيـرات التي تحدث في النـاتج المحلي الإجمالي ترجع إلي العوامل التفسيرية موضـع الدراسة. وتوكد الدالة علي وجود علاقة طردية بين الاستثمار الأجنبي المباشر كمتغير مستقل والناتج المحلي الإجمالي كمتغير تابع ، أن زيـادة الأستثمار الأجنبي المباشـر بنسبة . . ( \% يؤدي الي زيـادة الناتج المحلي الإجمالي بنسبة ؛\% وهذا يعني أن للاستثمار الأجنبي المباشر أثراً ايجابيا في الناتج المحلي الإجمالي، ويرتبط الاستثمار الأجنبي المباشر بعلاقة طرديا مع الناتج المحلي الإجمـالي وهو مـا يتفق مـع النظريـة الاقتصـادية، في حين يـرتط الاستثمار المحلي بعلاقة طرديـة مـع الناتج المحلي الإجمالي حيث ان زيـادة الاستثمار المحلي بنسبة . . 1\% يؤدي الي زيادة الناتج المحلي الإجمالي بنسبة ^^\% في السعودية .

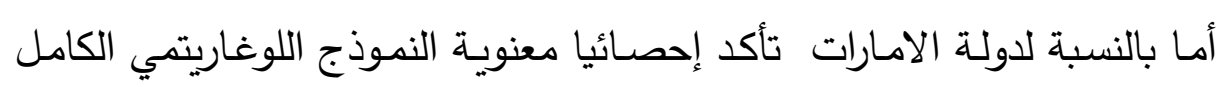
عند مستوي معنويـة ا ., . ، حيث بلغت قيمة "ف" المحسوبة حوالي 7, ؟ ا مما يدل علي كفاءة الدالة المقدرة في التعبير بدقة عن العلاقة بين المتغيرات المستقلة و الناتج المحلي الإجمـالي ، وإتضـح أن حـوالي ؟ 9\% مـن التغيرات التي تحدث في النـاتج المحلي الإجمالي ترجع إلي العوامل التفسيرية موضع الدراسة، وتوكد الدالة علي وجود 
علاقة طردية بين الاستثمار الأجنبي المباشر كمتغير مستقل والناتج المحلي الإجمالي كمتغير تابع ، أن زيـادة الأستثمار الأجنبي المباشر بنسبة . . 1\% يؤدي الي زيـادة الناتج المحلي الإجمالي بنسبة V\% وهذا يعني أن للاستثمار الأجنبي المباشر أثراً ايجابيا في الناتج المحلي الإجمالي، ويرتبط الاستثمار الأجنبي المباشر بعلاقة طرديا مـع النـاتج المحلي الإجمـالي وهو مـا يتفق مـع النظريـة الاقتصـادية، في حين يرتط الاستثمار المحلي بعلاقة طردية مع الناتج المحلي الإجمالي حيث ان زيادة الاستثمار

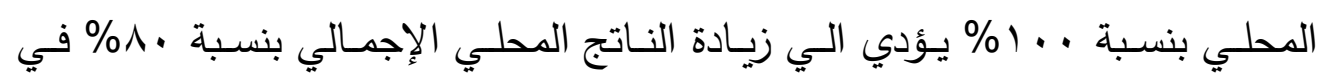

$$
\text { الامارات . الجدول رقم }
$$

جدول رقم(ץ) العومل المحددة للناتج المحلي الإجمالي لكل من السعودية والامارات والكوبت.

\begin{tabular}{|c|c|c|c|c|c|}
\hline $\mathbf{F}$ & $\bar{~} \mathbf{R}^{-2}$ & $\overline{\mathbf{R}^{2}}$ & النموذج & نوع الدالة & الدولة \\
\hline $\begin{array}{l}149.2 * \\
*\end{array}$ & $\begin{array}{c}0.9 \\
4\end{array}$ & $\begin{array}{c}0.9 \\
5\end{array}$ & $\begin{array}{r}\mathrm{GDP}=104864+1.55 \mathrm{FDi}+0.294 \mathrm{DI} \\
(1.61) \quad(17.1)^{* *}\end{array}$ & خطية & \multirow{2}{*}{ السية - المو } \\
\hline $\begin{array}{l}309.9^{*} \\
*\end{array}$ & $\begin{array}{c}0.9 \\
7\end{array}$ & $\begin{array}{c}0.9 \\
8\end{array}$ & $\begin{array}{l}\mathrm{GDP}=2.09+0.035 \mathrm{Log} \mathrm{FDi}+0.682 \mathrm{Log} \\
\mathrm{DI} \\
(2.14)^{*} \quad(20.8)^{* *}\end{array}$ & اللوغاريتمي & \\
\hline $61.3 * *$ & $\begin{array}{c}0.8 \\
7\end{array}$ & $\begin{array}{c}0.8 \\
9\end{array}$ & $\begin{array}{r}\mathrm{GDP}=108.9+5.76 \mathrm{FDi}+3.17 \mathrm{DI} \\
(2.16)^{*} \quad(9.42)^{* *}\end{array}$ & خطية & \multirow{2}{*}{ 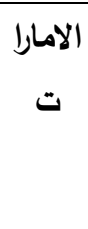 } \\
\hline $\begin{array}{c}149.6^{*} \\
*\end{array}$ & $\begin{array}{c}0.9 \\
4\end{array}$ & $\begin{array}{c}0.9 \\
5\end{array}$ & $\begin{array}{l}\text { GDP }=1.28+0.068 \log \mathrm{FDi}+0.802 \log \\
\text { DI } \\
\qquad(2.31)^{*} \quad(12.7)^{* *}\end{array}$ & اللوغاريتمي & \\
\hline $37.6 * *$ & $\begin{array}{c}0.8 \\
1\end{array}$ & $\begin{array}{c}0.8 \\
3\end{array}$ & $\begin{aligned} & \mathrm{GDP}=27685+ 21.5 \mathrm{FDi}+3.21 \mathrm{DI} \\
&(3.7)^{* *} \quad(5.59)^{* *}\end{aligned}$ & خطية & \multirow{2}{*}{ 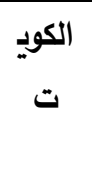 } \\
\hline $63.4 * *$ & $\begin{array}{c}0.8 \\
9\end{array}$ & $\begin{array}{c}0.8 \\
8\end{array}$ & $\begin{array}{c}\mathrm{GDP}=2.10+0.05 \log \mathrm{FDi}+1.45 \log \mathrm{DI} \\
(2.17) * *(6.81)^{* *}\end{array}$ & اللوغاريتمي & \\
\hline
\end{tabular}

$$
\text { المصدر : جدول رقم (r,r, () (بالملاحق }
$$

أما بالنسبة لدولة الكويت تأكد إحصائيا معنوية النموذج اللوغاريتمي الكامل عند

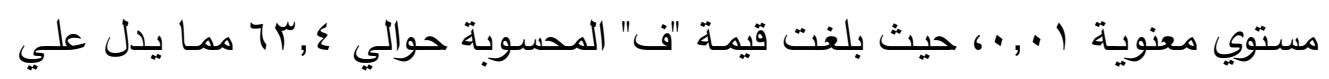
كفاءة الدالة المقدرة في التعبير بدقة عن العلاقة بين المتغيرات المستقلة و الناتج 


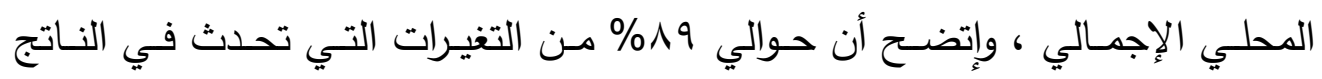
المحلي الإجمالي ترجع إلي العوامل التفسيرية موضع الدراسة، وتوكد الدالة علي وجود علاقة طردية بين الاستثمار الأجنبي المباشر كمتغير مستقل والناتج المحلي الإجمالي

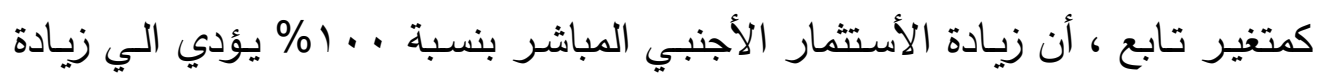
الناتج المحلي الإجمالي بنسبة ه\% وهذا يعني أن للاستثمار الأجنبي المباشر أثراً ايجابيا في الناتج المحلي الإجمالي، ويرتبط الاستثمار الأجنبي المباشر بعلاقة طرديا

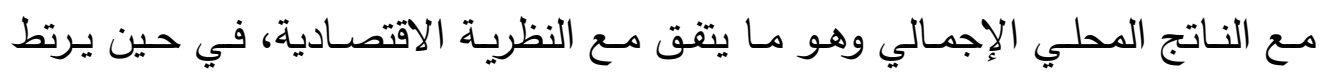
الاستثمار المحلي بعلاقة طردية مع الناتج المحلي الإجمالي حيث ان زيادة الاستثمار

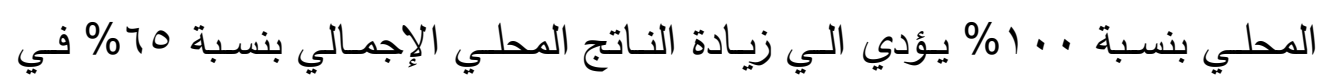
الكويت . r- النمـوذج الثالـث: يتكون هذا النمـوذج مـن اربع متغيرات مسـتقلة بوصفها أهم

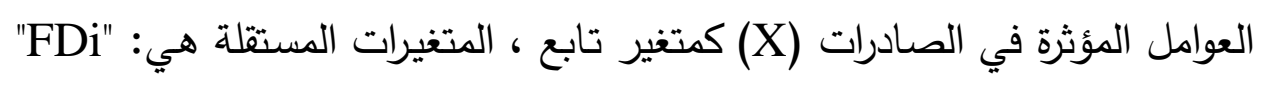
الاسـتثمار الأجنبـي المباشـر "DI" الاستثمار المحلي , الناتج المحلي الإجمالي

$$
\text { (GDP). (لاستهلاك النهائي (GD) }
$$

يتضـح مـن الجدول (r) لدولـة السعودية أن تطبيق نموذج دالـة أثر الاستثمار الأجنبي المباشر و الناتج المحلي الإجمالي والاستثمار المحلي والاستهلاك النهائي

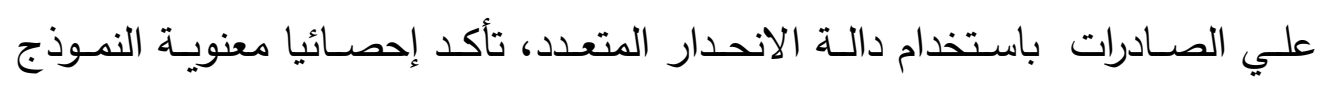
الخطي عند مستوي معنويـة ا .,. •، حيث بلغت قيمة "ف" المحسوبة حوالي كY,V مما يدل علي كفاءة الدالة المقدرة في التعبير بدقة عن العلاقة بين المتغيرات المستقلة و الصادرات ، وإتضح أن حوالي 99\% من التغيرات التي تحدث في الصـادرات ترجع إلي العوامل التفسيرية موضـع الدراسـة. وتوكد الدالـة علي وجود علاقـة طرديـة بين الصـادرات وكل من الاستثمار الأجنبي المباشر والناتج المحلي الإجمالي، حيث أن زيـادة الأسـتثمار الأجنبـي المباشـر بنسـبة . . 1\% يـؤدي الـي زيـادة النـاتج المحلـي 
الإجمالي بنسبة ^§ (\% وهذا يعني أن للاستثمار الأجنبي المباشر أثراً ايجابيا في الصادرات، في حين ان زيادة الناتج المحلي الإجمالي بنسبة . . 1\% يؤدي الي زيادة الصادرات بنسبة V • (1\%. أما بالنسبة الي الاستثمار المحلي لم تتضح معنوية التأثير علي الصـادرات، بينما تبين وجود علاقة عكسية بين الصـادرات والاستهلاك النهائي وهو ما يتفق مع النظرية الاقتصادية، حيث أن زيادة الاستهلاك النهائي بنسبة . . 1 يؤدي الي انخفاض الصادرات بنسبة ؟9\% أمـا بالنسبة لدولـة الامـارات ت تأكد إحصـائيا معنويـة النمـوذج اللوغـاريتمي عند

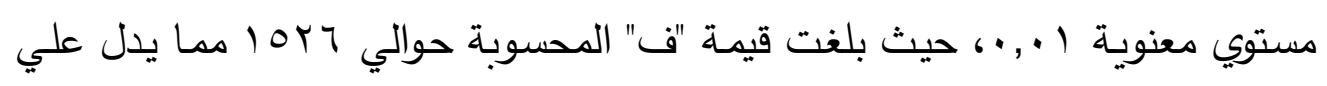
كفاءة الدالة المقدرة في التعبير بدقة عن العلاقة بين المتغيرات المستقلة و الصادرات ، وإتضـح أن حوالي 99\% من التغيرات التي تحدث في الصـادرات ترجع إلي العوامل التفسيرية موضع الدراسـة. وتوكد الدالة علي وجود علاقة طردية بين الصـادرات وكل من الاستثمار الأجنبي المباشر والناتج المحلي الإجمالي، حيث أن زيـادة الأستثمار الأجنبي المباشر بنسبة . . 1\% يؤدي الي زيادة الناتج المحلي الإجمالي بنسبة ؟. ا \% وهذا يعني أن للاستثمار الأجنبي المباشر أثراً ايجابيا في الصادرات، في حين ان زيادة

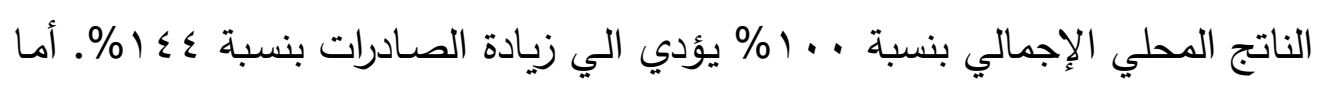
بالنسبة الي الاستثمار المحلي لم تتضـح معنويـة التأثير علي الصـادرات، بينمـا تبين وجود علاقة عكسية بـين الصـادرات والاستهلاك النهائي وهو مـا يتفق مـع النظريـة الاقتصـادية، حيث أن زيـادة الاستهلاك النهائي بنسبة . . 1\% يؤدي الـي انخفـاض الصادرات بنسبة ؟r\%. أما بالنسبة لدولة الكويت تأكد إحصائيا معنوية النموذج اللوغاريتمي عند مستوي

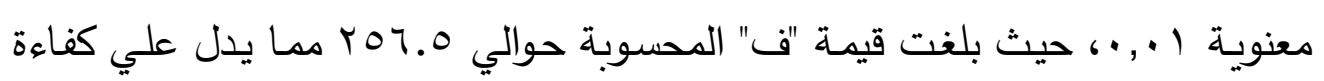
الدالـة المقدرة في التعبيـر بدقـة عـن العلاقـة بـين المتغيـرات المستقلة و الصـادرات ، 
وإتضح أن حوالي 9\% من التغيرات التي تحدث في الصسادرات ترجع إلي العوامل

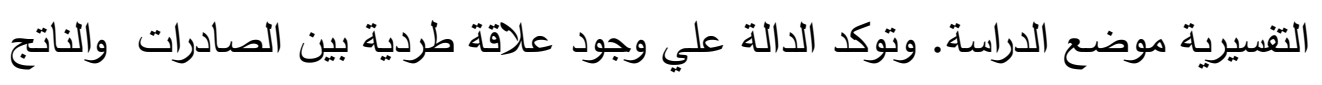

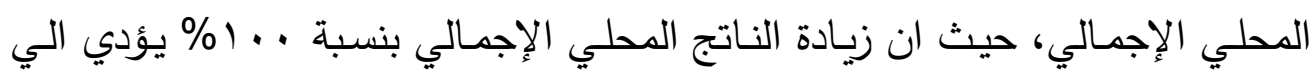

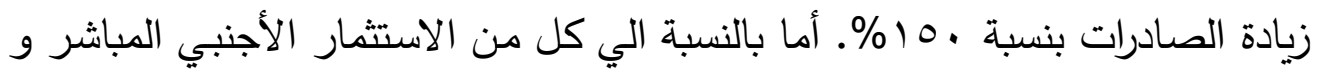

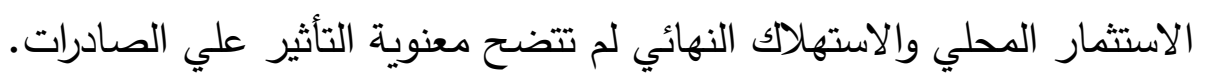
الجدول رقم (ץ) العومل المحددة للصادات لكل من السعودية والامارات والكويت.

\begin{tabular}{|c|c|c|c|c|c|}
\hline $\mathbf{F}$ & $\mathbf{R}^{-2}$ & $\mathbf{R}^{2}$ & النموذج & نوع الدالة & الدولة \\
\hline $\begin{array}{c}472.7^{*} \\
*\end{array}$ & 0.99 & 0.99 & 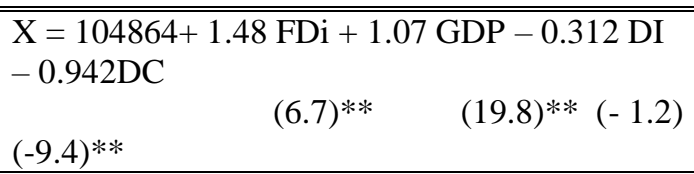 & خطية & السعودية \\
\hline $\begin{array}{c}268.1^{*} \\
*\end{array}$ & 0.98 & 0.98 & $\begin{array}{l}\mathrm{X}=2.09+0.017 \log \mathrm{FDi}+2.21 \log \mathrm{DI}- \\
0.302 \log \mathrm{DI}-0.964 \log \mathrm{C} C \\
\quad{ }^{(4.6)^{* *}} \quad(10.4)^{* *} \quad(- \\
1.2) \quad(-3.8)^{* *}\end{array}$ & اللوغاريتمي & \\
\hline $1515^{* *}$ & 0.99 & 0.99 & $\begin{array}{l}\mathrm{X}=-20743-0.42 \mathrm{FDi}+1.44 \mathrm{GDP}-0.48 \mathrm{DI}- \\
0.49 \mathrm{DC} \\
\begin{array}{cc} \\
3.5)^{* *} & (-5.57)^{* *}\end{array}\end{array}$ & خطية & الامارات \\
\hline $1526^{* *}$ & 0.99 & 0.99 & $\begin{array}{l}\mathrm{X}=-0.84+0.013 \log \mathrm{FDi}+1.44 \log \mathrm{GDP}- \\
0.07 \log \mathrm{DI}-0.24 \operatorname{LogDC} \\
\quad{ }^{*}(2.45)^{*} \\
0.91) \quad(12.8)^{* *} \quad(-\end{array}$ & اللوغاريتمي & \\
\hline $\begin{array}{c}148.6^{*} \\
*\end{array}$ & 0.97 & 0.97 & $\begin{array}{l}\mathrm{X}=6862+3.56 \mathrm{FDi}+0.84 \mathrm{GDP}-0.41 \mathrm{DI}- \\
0.26 \mathrm{DC} \\
(-1.15)\end{array}$ & خطية & الكويت \\
\hline $\begin{array}{c}256.5^{*} \\
*\end{array}$ & 0.98 & 0.98 & $\begin{array}{l}\mathrm{X}=-0.97+0.003 \log \mathrm{FDi}+1.5 \log \mathrm{DI}-0.13 \\
\log \mathrm{DI}-0.25 \log \mathrm{DC} \\
\quad(0.22) \quad(12.9)^{* *} \quad(- \\
1.5) \quad(-1.4)\end{array}$ & اللوغاريتمي & \\
\hline
\end{tabular}

$$
\text { المصدر : جدول رقم (r, r, ا)بالملحق }
$$

ع - النموذج الرابع: يتكون هذا النموذج من ثلاثة متغيرات مستقلة بوصنها أهم العوامل

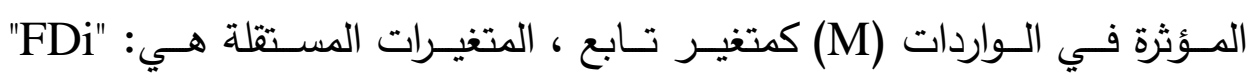


الاسـتثمار الأجنبـي المباشـر , النـاتج المحلـي الإجمـالي (GDP). الاستهلالك النهائي (DC).

يتضـح من الجدول (ع) لدولة السعودية أن تطبيق نموذج دالة أثر الاستثمار

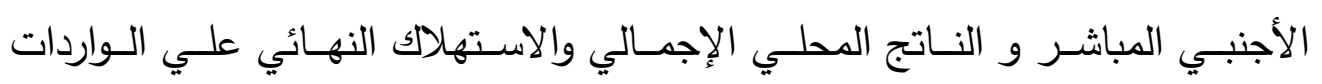
باستخدام دالة الانحدار المتعدد، تأكد إحصائيا معنوية النموذج اللوغاريتمي عند مستوي الإني

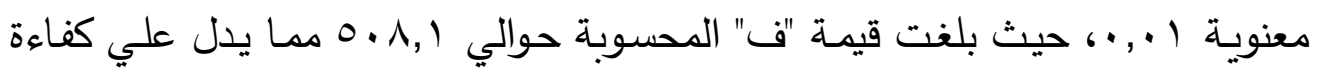
الدالة المقدرة في التعبير بدقة عن العلاقة بين المتغيرات المستقلة و الواردات ، وإتضح أن حوالي 91\% من التغيرات التي تحدث في الواردات ترجع إلي العوامل التفسيرية

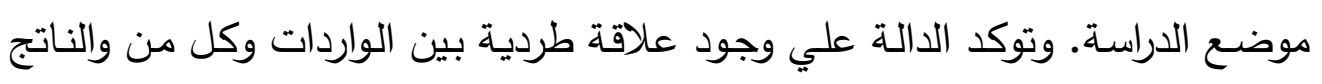

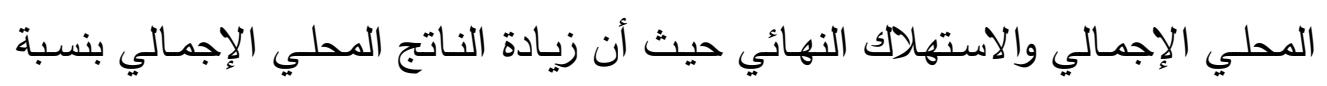

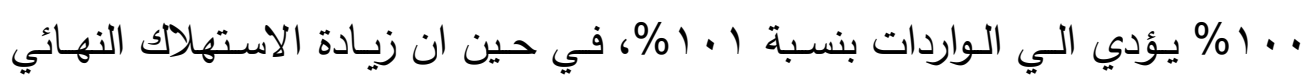

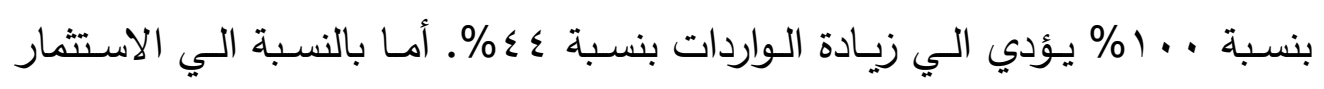
الاجنبي المباشر لم تتضح معنوية التأثير علي الواردات.

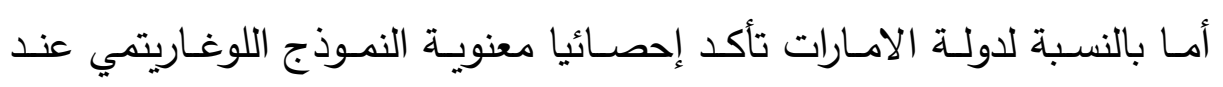

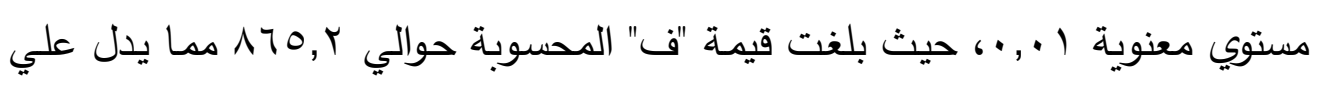

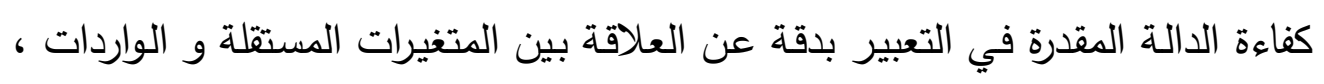

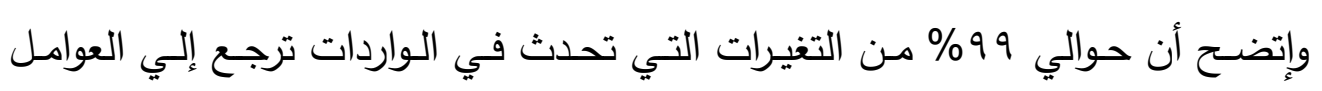

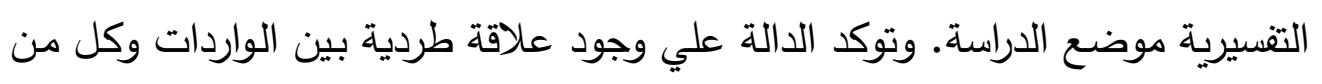

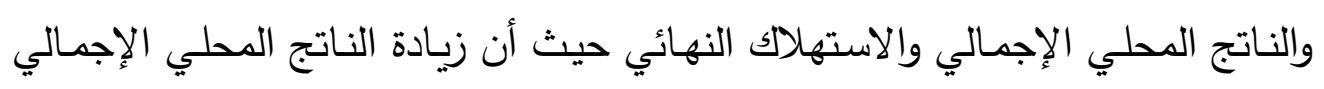

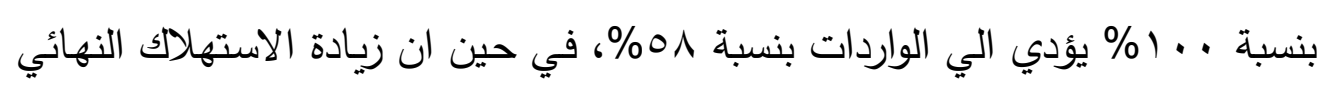

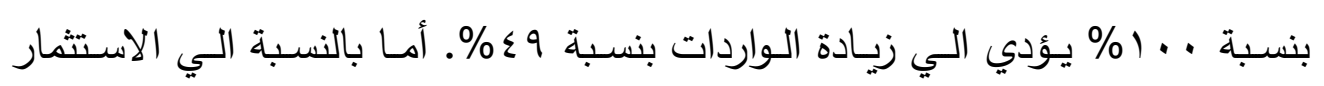
الاجنبي المباشر لم تتضح معنوية التأثير علي الواردات. 
أما بالنسبة لدولة الكويت تأكد إحصائيا معنوية النموذج اللوغاريتمي عند مستوي معنويـة ا +., •، حيث بلغت قيمـة "ف" المحسوبة حوالي 19,9 ممـا يدل علي كفاءة الدالة المقدرة في التعبير بدقة عن العلاقة بين المتغيرات المستقلة و الواردات ، وإتضح أن حوالي § 9\% من التغيرات التي تحدث في الواردات ترجع إلي العوامل التفسيرية موضع الدراسة. وتوكد الدالة علي وجود علاقة طردية بين الواردات والاستهلاك النهائي حيث أن زيـادة الاسـتهلاك النهائي بنسبة . . 1\% يؤدي الـي زيـادة الـواردات بنسبة 7 ا \% . أمـا بالنسبة الي الاستثمار الاجنبي المباشـر والنـاتج المحلي الإجمالي لـ لـ تتضح معنوية التأثير علي الواردات.

الجدول رقم (ع) العومل المحدة للواردات لكل من السعودية والامارات والكويت.

\begin{tabular}{|c|c|c|c|c|c|}
\hline $\mathbf{F}$ & $\mathbf{R}^{-2}$ & $\mathbf{R}^{2}$ & النموذج & نوع الدالة & الدولة \\
\hline $172.3 * *$ & 0.96 & $\begin{array}{c}0.9 \\
7\end{array}$ & $\begin{array}{l}\mathrm{M}=-43041-0.332 \mathrm{FDi}+0.27 \\
\mathrm{GDP}+0.18 \mathrm{DC} \\
(5.07)^{* *}(2.15)^{*}\end{array}$ & خطية & \multirow[t]{2}{*}{ السعودية } \\
\hline $508.1^{* *}$ & 0.98 & $\begin{array}{c}0.9 \\
9\end{array}$ & $\begin{array}{l}\mathrm{M}=-3.1+0.04 \log \mathrm{FDi}+1.01 \\
\log \mathrm{DI}+0.44 \operatorname{LogDC} \\
(5.45)^{* *} \quad(0.24) \\
(2.58) *\end{array}$ & اللوغاريتمي & \\
\hline $495.3 * *$ & 0.98 & $\begin{array}{c}0.9 \\
9\end{array}$ & $\begin{array}{l}\mathrm{M}=-29454-0.41 \mathrm{FDi}+0.58 \\
\mathrm{GDP}+0.49 \mathrm{DC} \\
(6.1)^{* *}(3.19)^{* *}\end{array}$ & خطية & \multirow[t]{2}{*}{ الامارات } \\
\hline $865.2 * *$ & 0.99 & $\begin{array}{c}0.9 \\
9\end{array}$ & $\begin{array}{l}\mathrm{M}=-1.13+0.014 \mathrm{Log} \mathrm{FDi}+0.73 \\
\log \mathrm{GDP}+0.45 \operatorname{LogDC} \\
(4.6)^{* *} \quad(2.84) *\end{array}$ & اللوغاريتمي & \\
\hline $148.6^{* *}$ & 0.97 & $\begin{array}{c}0.9 \\
7\end{array}$ & $\begin{array}{l}\mathrm{M}=-15697+2.68 \mathrm{FDi}-0.09 \\
\mathrm{GDP}+0.98 \mathrm{DC} \\
\left(7.5^{* *}\right)\end{array}$ & خطية & \multirow[t]{2}{*}{ الكويت } \\
\hline $256.5^{* *}$ & 0.98 & $\begin{array}{c}0.9 \\
8\end{array}$ & $\begin{array}{c}\mathrm{M}=-2.92+0.026 \log \mathrm{FDi}+1.08 \\
\log \text { GDP+ } 1.65 \operatorname{LogDC} \\
(1.3) \\
(-0.55) \quad(6.6)^{* *}\end{array}$ & اللوغاريتمي & \\
\hline
\end{tabular}




$$
\text { المصدر: جدول رقم (r, r, () (بالملحق }
$$

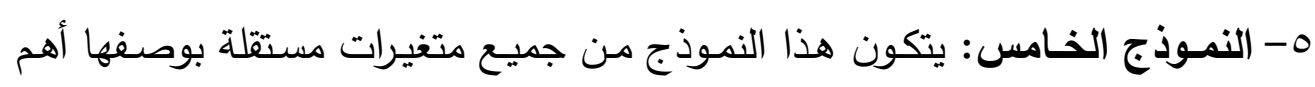

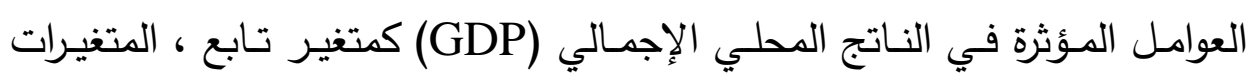

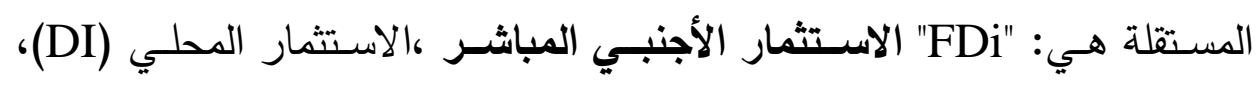

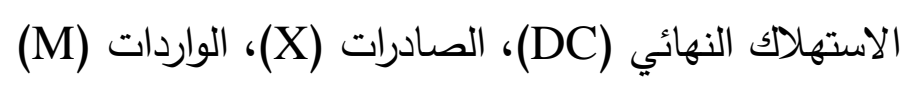

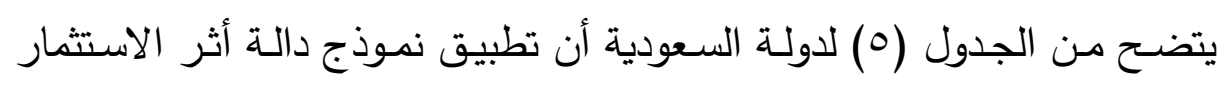

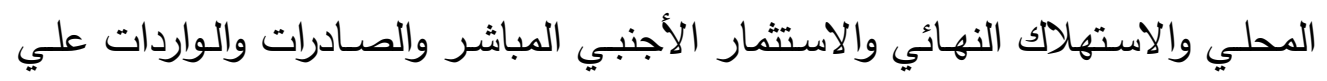

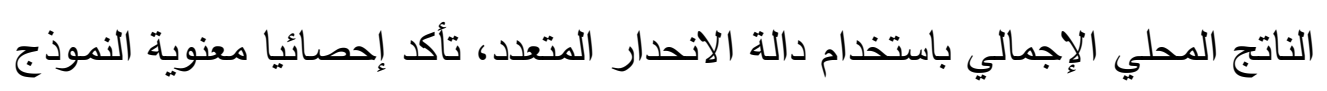

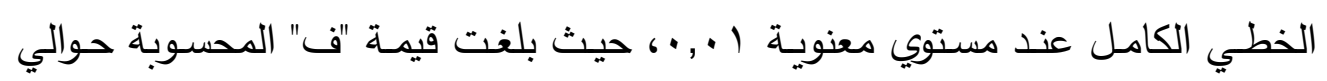

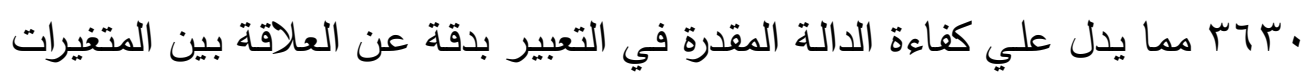

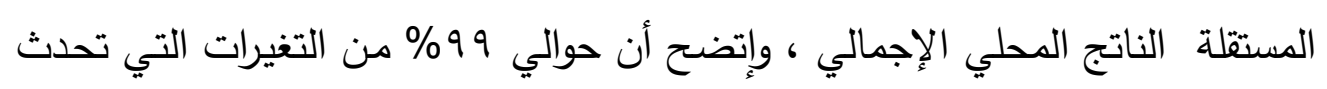

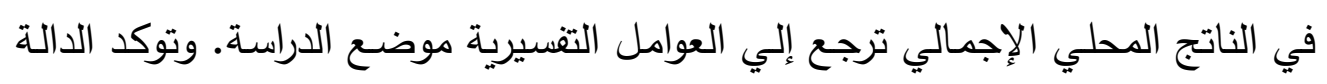

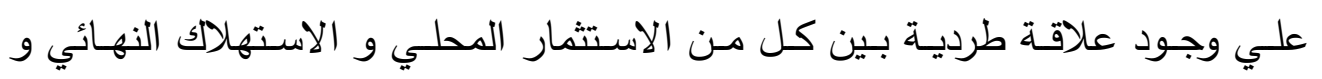

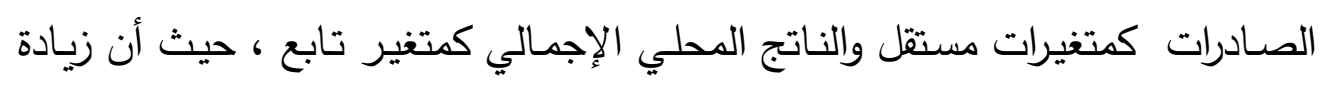

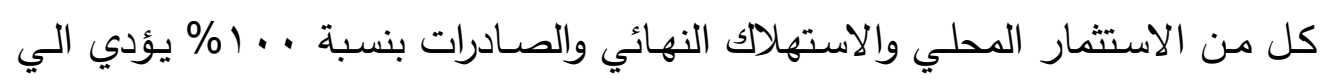

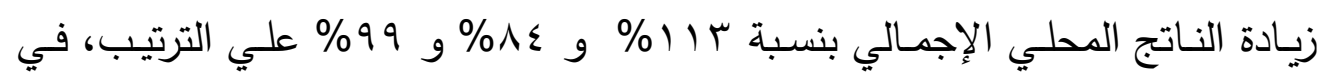

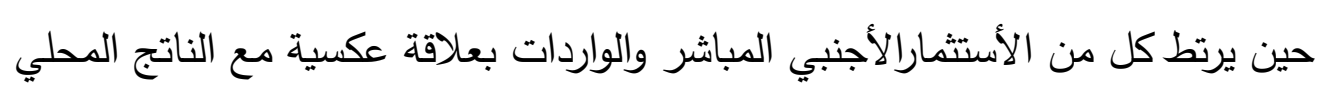

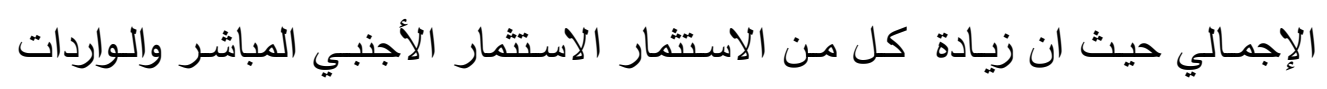

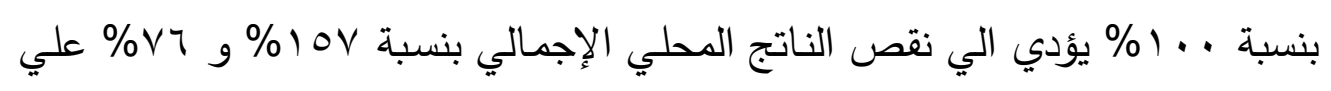
الترتيب. أما بالنسبة لدولة الامارات تأكد إحصائيا معنوية النموذج الخطي الكامل عند

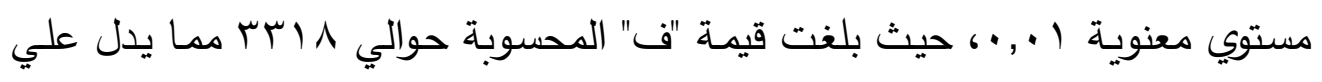


كفاءة الدالة المقدرة في التعبير بدقة عن العلاقة بين المتغيرات المستقلة الناتج المحلي الإجمـالي ، وإتضــح أن حـوالي 99\% مـن التغيـرات التي تحدث في النـاتج المحلـي الإجمالي ترجع إلي العوامل التفسيرية موضـع الدراسة. وتوكد الدالة علي وجود علاقة طردية بين كل من الاستثمار المحلي و الاستهلاك النهائي و الصـادرات كمتغيرات مستقل والنـاتج المحلـي الإجمـالي كمتغيـر تـابع ، حيث أن زيـادة كل مـن الاستتمار المحلي والاستهلاك النهائي والصادرات بنسبة .. 1\% يؤدي الي زيادة الناتج المحلي الإجمـالي بنسـبة r\%\% و 909 و • (1\% علي الترتيب، في حين يـرتط الـواردات بعلاقة عكسية مـع الناتج المحلي الإجمالي حيث ان زيـادة كل من الواردات بنسبة

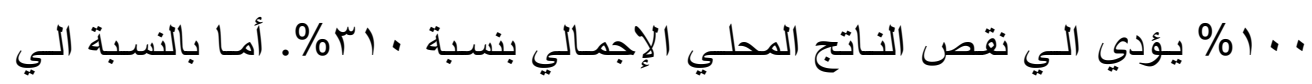
الاستثمار الاجنبي المباشر لم تتضح معنوية التأثير علي الناتج المحلي الإجمالي. أما بالنسبة لدولة الكويت تأكد إحصائيا معنوية النموذج للوغاريتمي عند مستوي معنويـة ا +., •، حيث بلغت قيمـة "ف" المحسوبة حوالي ه ـ ب ب ممـا يدل علي كفاءة الدالـة المقدرة في التعبير بدقـة عن العلاقـة بين المتغيـرات المستقلة النـاتج المحلي الإجمـالي ، وإتضــح أن حـوالي 99\% مـن التغيـرات التي تحدث في النـاتج المحلـي الإجمالي ترجع إلي العوامل التفسيرية موضع الدراسة. وتوكد الدالة علي وجود علاقة طرديـة بـين كل مـن الاستثمار المحلي و الاستهلاك النهائي و الاستثمار الأجنبي المباشر و الصادرات كمتغيرات مستقل والناتج المحلي الإجمالي كمتغير تابع ، حيث أن زيادة كل من الاستثمار المحلي والاستهلاك النهائي و الاستثمار الأجنبي المباشر والصـادرات بنسبة . . 1\% يؤدي الي زيـادة الناتج المحلي الإجمالي بنسبة 9 (1\% و و

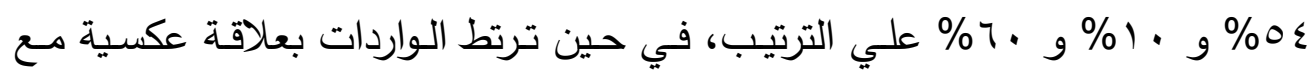
الناتج المحلي الإجمالي حيث ان زيادة الواردات بنسبة . 1 \% يؤدي الي نقص الناتج

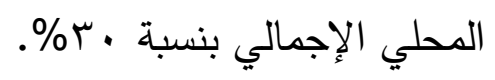


الجدول رقم (0) العومل المحددة للناتج المحلي الاجمالي لكل من السعودية والامارات الكوبت

\begin{tabular}{|c|c|c|c|c|c|}
\hline $\mathbf{F}$ & $\mathbf{R}^{-2}$ & $\mathbf{R}^{2}$ & النموذج & الدالة & الدولة \\
\hline $3630 * *$ & 0.99 & 0.99 & 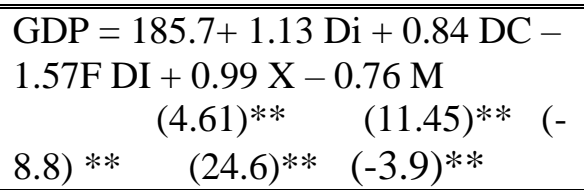 & خطية & \multirow[t]{2}{*}{ السعودية } \\
\hline $\begin{array}{c}918.1^{*} \\
*\end{array}$ & 0.99 & 0.99 & $\begin{array}{l}\text { GDP }=0.58+0.16 \log \mathrm{Di}+0.37 \mathrm{Log} \mathrm{DC}- \\
0.025 \log \mathrm{FDI}-0.39 \operatorname{LogX}+0.041 \mathrm{M} \\
\begin{array}{l}(1.2) \quad(3.05)^{*} \quad(- \\
2.84)^{*} \quad(6.82)^{* *}(0.31)\end{array}\end{array}$ & اللوغاريتمي & \\
\hline $3318^{* * *}$ & 0.99 & 0.99 & $\begin{array}{l}\mathrm{GDP}=8688+0.265 \mathrm{Di}+0.591 \\
\mathrm{DC}+0.11 \mathrm{~F} \mathrm{DI}+0.84 \mathrm{X}-0.32 \mathrm{M} \\
\begin{array}{ccc}(3.12)^{* *} & (5.24)^{* *} \\
(0.35) & (10.2)^{* *} & (-2.18)^{*}\end{array}\end{array}$ & خطية & \multirow[t]{2}{*}{ الامارات } \\
\hline $2801 * *$ & 0.99 & 0.99 & $\begin{array}{c}\text { GDP }=0.34+0.049 \log \mathrm{Di}+0.39 \log \mathrm{DC} \\
-0.007 \log \mathrm{FDI}+0.84 \operatorname{LogX}-0.31 \mathrm{M} \\
(1.61) \quad(4.41)^{* *} \\
(-2.10) \quad(9.1)^{* *}\left(-2.38^{*}\right)\end{array}$ & اللوغاريتمي & \\
\hline $1676^{* *}$ & 0.99 & 0.99 & 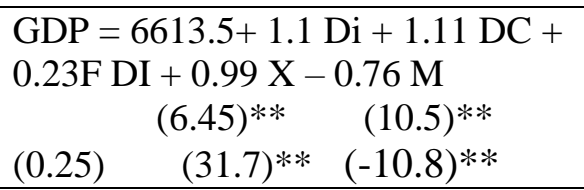 & خطية & \multirow[t]{2}{*}{ الكويت } \\
\hline $2605 * *$ & 0.99 & 0.99 & $\begin{array}{c}\mathrm{GDP}=0.65+0.19 \log \mathrm{Di}+0.54 \log \mathrm{DC} \\
+0.01 \log \mathrm{FDI}-0.60 \operatorname{LogX}-0.30 \mathrm{M} \\
(6.7)^{* *} \quad(9.1)^{* *} \\
(3.3)^{* *} \quad(34.5)^{* *}(9.2)^{* * *}\end{array}$ & اللوغاريتمي & \\
\hline
\end{tabular}

المصدر : جدول رقم (r, r, ( )بالملحق 


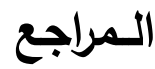

1- الزهراني، بندر، الاستثمارات الأجنبية المباشرة ودورها في النمو الاقتصادي في

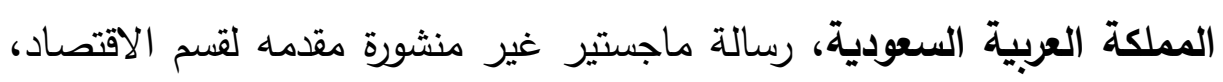
كلية إدارة الإعمال، جامعة الملك سعود، ع . . T.

ץ- الثبيب، دريد، الاستثمار والتحليل الاستثماري، الطبعة الأولى، دار اليازوري

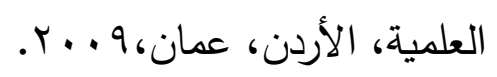

r- المحتسب، بثينة، "اثر الاستثمار الأجنبي المباشر في النمو الاقتصادي في

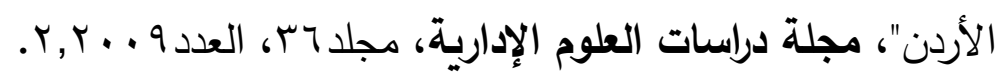

4- Markusen, G. and Venables, A.(1997), "Foreign Direct Investment As a Catalyst for Industrial Development", European Economic Review, Volume 43, Issue 2, 1997>

0- صندوق النقد العربي، اعداد متغرقة. 


\section{الملاحق}

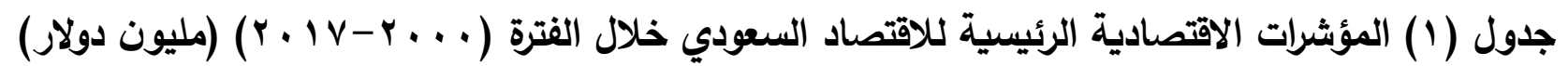

\begin{tabular}{|c|c|c|c|c|c|c|}
\hline الواردات & الصادرات & الاستثمار الاجنبي & الاستهلاك & الاستثمار المحلي & الناتج المحلي الاجمالي & 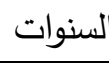 \\
\hline 30238 & 78756 & 200 & 103766 & 28210 & 173286 & $r \ldots$ \\
\hline 31223 & 72838 & 504 & 118686 & 35174 & 186489 & r... \\
\hline 32293 & 72561 & 453 & 118645 & 37096 & 188551 & $r \ldots r$ \\
\hline 41704 & 93368 & 778.5 & 123905 & 41631 & 214573 & $r \ldots r$ \\
\hline 47376 & 126166 & 1942 & 135334 & 45411 & 250339 & $r \ldots \varepsilon$ \\
\hline 59459 & 180522 & 12097 & 153106 & 50274 & 304531 & r...o \\
\hline 69800 & 211024 & 18293 & 176603 & 62475 & 356156 & $r \ldots r$ \\
\hline 90214 & 233114 & 24319 & 198218 & 81682 & 383871 & $r \ldots v$ \\
\hline 115134 & 313447 & 39456 & 224374 & 97391 & 468800 & r... \\
\hline 95552 & 189701 & 36458 & 238149 & 93984 & 369178 & $r \ldots q$ \\
\hline 97077 & 249699.5 & 29233 & 247760 & 99783 & 434666 & $r \cdot 1$. \\
\hline 197977 & 376187 & 16308 & 310397 & 180900 & 669507 & $r \cdot 11$ \\
\hline 215206 & 399419 & 12182 & 344472 & 182363 & 711049 & $r \cdot 1 r$ \\
\hline 229901 & 387644 & 8865 & 391269 & 195324 & 746647 & $r \cdot 1 r$ \\
\hline 247997 & 363553 & 8012 & 436190 & 200714 & 756350 & $r .1 \leq$ \\
\hline 250506 & 218024 & 8141 & 454652 & 223832 & 646002 & $r .10$ \\
\hline
\end{tabular}




\begin{tabular}{|l|l|l|l|l|l|l|}
\hline 198110 & 200860 & 7453 & 442690 & 199495 & 644935 & r.1r \\
\hline 196146 & 239271 & 1419 & 451899 & 191714 & 686739 & r.IV \\
\hline
\end{tabular}

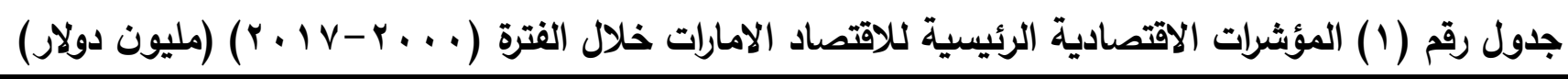

\begin{tabular}{|c|c|c|c|c|c|c|}
\hline الواردات & الصادرات & الاستثمار الاجنبي & الاستهلاكS & الاستثمار المحلي & الناتج المحلي الاجمالي & 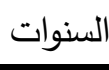 \\
\hline 35009 & 49834 & -515 & 41541 & 16359 & 70512 & r... \\
\hline 37293 & 48774 & 1148 & 43666 & 17146 & 69546 & $r \ldots 1$ \\
\hline 42652 & 52163 & 95 & 46183 & 17333 & 71567 & $r \ldots r$ \\
\hline 52074 & 66755 & 4256 & 49912 & 18652 & 80224 & $r \ldots r$ \\
\hline 72082 & 90948 & 10004 & 67486 & 23352 & 104180 & $r \ldots \varepsilon$ \\
\hline 84654 & 117288 & 10899 & 79447 & 27099 & 138331 & $r \ldots o$ \\
\hline 100057 & 145587 & 12806 & 91276 & 34762 & 168384 & $r \ldots r$ \\
\hline 132500 & 178630 & 14186 & 115801 & 42454 & 196643 & $r \ldots v$ \\
\hline 177000 & 239212 & 5063 & 131763 & 71178 & 250517 & $r \ldots \lambda$ \\
\hline 150000 & 192192 & 1134 & 139347 & 85953 & 225631 & r...q \\
\hline 162750 & 213141 & 8797 & 146997 & 101064 & 248420 & $r \cdot 1$. \\
\hline 286450 & 314835 & 7152 & 240186 & 80025 & 348595 & $r .11$ \\
\hline 324969 & 365192 & 9567 & 256604 & 86972 & 383799 & $r \cdot 1 r$ \\
\hline 312499 & 395888 & 9765 & 227918 & 91033 & 402340 & $r .1 T$ \\
\hline
\end{tabular}




\begin{tabular}{|c|c|c|c|c|c|c|}
\hline 348618 & 419170 & 11072 & 249884 & 99306 & 419741 & r.1 \\
\hline 322124 & 342001 & 8551 & 247661 & 107692 & 375230 & $r \cdot 10$ \\
\hline 273274 & 362069 & 9605 & 171895 & 88053 & 348744 & $r \cdot 1 r$ \\
\hline 281473 & 385604 & 10354 & 183717 & 96359 & 384207 & $r \cdot 1 V$ \\
\hline
\end{tabular}

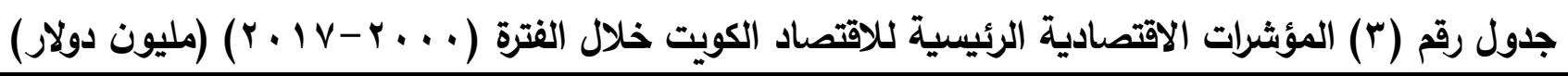

\begin{tabular}{|c|c|c|c|c|c|c|}
\hline الواردات & الصادرات & الاستثمار الاجنبي & الاستهلاك & الاستثمار المحلي & الناتج المحلي الاجمالي & السنوات \\
\hline 7157 & 19476 & 16 & 23763 & 4022 & 37018 & $r \ldots$ \\
\hline 7869 & 16245 & -112 & 24410 & 4993 & 34076 & r... \\
\hline 9001 & 15363 & 3.6 & 28545 & 6531 & 35173 & $r \ldots r$ \\
\hline 10987 & 20956 & -67 & 31469 & 7962 & 41743 & $r \ldots r$ \\
\hline 12631 & 29001 & 23.8 & 34045 & 10809 & 59439 & r... \\
\hline 15801 & 45301 & 234 & 38673 & 13276 & 80799 & r...o \\
\hline 17243 & 56446 & 121.3 & 43121 & 16494 & 101549 & $r \ldots r$ \\
\hline 21362 & 62489 & 111.5 & 50363 & 24285 & 114608 & r... \\
\hline 24840 & 87039 & -6 & 61246 & 27425 & 148921 & $r \ldots \Lambda$ \\
\hline 20341 & 50305 & 1113.6 & 63224 & 15235 & 109482 & r...q \\
\hline 32660 & 74640 & 1304.6 & 58548 & 23716 & 124244 & $r \cdot 1$. \\
\hline 39900 & 112800 & 3259.1 & 61410 & 26316 & 160626 & $r .11$ \\
\hline 42046 & 129286 & 2872.6 & 68323 & 27675 & 183238 & $r \cdot 1 r$ \\
\hline 46570 & 123389 & 1433.6 & 72319 & 24900 & 174128 & $r .1 r$ \\
\hline
\end{tabular}




\begin{tabular}{|l|l|l|l|l|l|l|}
\hline 51186 & 111090 & 953.5 & 77888 & 25884 & 163677 & r.1 \\
\hline 51635 & 62036 & 310.6 & 75154 & 28524 & 114079 & r.10 \\
\hline 53090 & 52113 & 418.7 & 77607 & 32777 & 109407 & r.17 \\
\hline 57497 & 60277 & 348.1 & 82003 & 34752 & 119535 \\
\hline
\end{tabular}

